\title{
Synthesis, Structures and Optical Properties of Ruthenium(II) Complexes of the Tris(1-Pyrazolyl)methane Ligand
}

Benjamin J. Coe, ${ }^{*, \dagger}$ Madeleine Helliwell, ${ }^{\dagger}$ Martyn K. Peers, ${ }^{\dagger}$ James Raftery, ${ }^{\dagger}$ Daniela Rusanova, ${ }^{\dagger}$ Koen Clays, ${ }^{\ddagger}$ Griet Depotter, ${ }^{\ddagger}$ and Bruce S. Brunschwig ${ }^{\S}$

$\dagger$ School of Chemistry, University of Manchester, Oxford Road, Manchester M13 9PL, U.K., and

$\$$ Department of Chemistry, University of Leuven, Celestijnenlaan 200D, B-3001 Leuven, Belgium

$\S$ Molecular Materials Research Center, Beckman Institute, MC 139-74, California Institute of Technology, 1200 East California Boulevard, Pasadena, California 91125

* Address correspondence to this author. E-mail: b.coe@manchester.ac.uk. 
Four new complex salts $\left[\mathrm{Ru} \mathrm{u}^{\prime \prime} \mathrm{Cl}(\mathrm{Tpm})\left(\mathrm{L}^{\mathrm{A}}\right)_{2}\right]\left[\mathrm{PF}_{6}\right]_{\mathrm{n}}[\mathrm{Tpm}=\operatorname{tris}(1-$ pyrazolyl)methane; $\mathrm{n}=$ $1, L^{A}=$ pyridine (py) 1 or ethyl isonicotinate (EIN) 2; $n=3, L^{A}=N$-methyl-4,4'bipyridinium $\left(\mathrm{MeQ}^{+}\right) 3$ or $\mathrm{N}$-phenyl-4,4'-bipyridinium $\left(\mathrm{PhQ}^{+}\right)$4] have been prepared and characterized. Electronic absorption spectra show intense $d \rightarrow \pi^{\star}$ metal-toligand charge-transfer (MLCT) absorption bands, while cyclic voltammetry reveals a reversible $\mathrm{Ru}^{\mathrm{IIIII}}$ wave, accompanied by quasireversible or irreversible $\mathrm{L}^{\mathrm{A}}$-based reductions for all except 1. Single crystal X-ray structures have been obtained for $\mathbf{1} \cdot \mathrm{Me}_{2} \mathrm{CO}, 2$ and $\mathbf{3} \cdot \mathrm{Me}_{2} \mathrm{CO}$. For $\mathbf{2}-\mathbf{4}$, molecular first hyperpolarizabilities $\beta$ have been measured in acetonitrile solutions via the hyper-Rayleigh scattering (HRS) technique at $800 \mathrm{~nm}$. Stark (electroabsorption) spectroscopic studies on the MLCT bands in frozen butyronitrile allow the indirect estimation of static first hyperpolarizabilities $\beta_{0}$. The various physical data obtained for $\mathbf{3}$ and $\mathbf{4}$ are compared with those reported previously for related cis-\{Ru" $\left.\left(\mathrm{NH}_{3}\right)_{4}\right\}^{2+}$ species (Coe, B. J. et al. J. Am. Chem. Soc. $2005,127,4845)$. TD-DFT calculations on the complexes in 1-4 confirm that their lowest energy absorption bands are primarily $\mathrm{Ru} u^{\prime \prime} \rightarrow L^{\mathrm{A}} \mathrm{MLCT}$ in character, while $\mathrm{Ru}$ " $\rightarrow$ Tpm MLCT transitions are predicted at higher energies. DFT agrees with the Stark, but not the HRS measurements, in showing that $\beta_{0}$ increases with the electron-accepting strength of $L^{A}$. The $2 D$ nature of the chromophores is evidenced by dominant $\beta_{x x y}$ tensor components. 


\section{Introduction}

The precious metal ruthenium exhibits a particularly rich coordination and organometallic chemistry, encompassing a huge range of stable complexes with every type of ligand imaginable. ${ }^{1}$ The relatively high stability and comparative ease of synthesis of Ru complexes has allowed this area of chemistry to develop freely. Besides their fundamental scientific value, such complexes are of interest for practical applications in various important fields including catalysis, ${ }^{2}$ biology/medicine, ${ }^{3}$ and technologies that rely upon the photophysical/chemical properties of $\mathrm{Ru}^{\mathrm{II}}$-containing chromophores. ${ }^{4}$ The latter cover themes such as organic light-emitting diodes ${ }^{5}$ and dye-sensitized solar cells, ${ }^{6}$ which typically involve complexes of chelating polypyridyl ligands, especially $2,2^{\prime}$-bipyridyl. Such species have fascinating electronic absorption, emission and electron/energy-transfer properties that are based on low energy metal-to-ligand charge-transfer (MLCT) excited states. Tuning the properties of these states by judicious changes in ligand structure has become a highly developed area of coordination chemistry. ${ }^{4}$

In addition to the above-mentioned areas, $\mathrm{Ru}$ complexes have attracted attention for their nonlinear optical (NLO) behavior. ${ }^{7}$ Such phenomena involve changing the fundamental properties of laser beams, useful in harmonic generators and electrooptic switches, with emerging applications like biological imaging. ${ }^{8}$ Our ongoing investigations in this field have included a series of complexes with V-shaped dipolar structures based on electron-donating cis- $\left\{\mathrm{Ru}^{\mathrm{II}}\left(\mathrm{NH}_{3}\right)_{4}\right\}^{2+}$ centers. ${ }^{9}$ These complexes show intense, broad MLCT absorption profiles in the visible region, comprising overlapping bands. The MLCT transitions are associated with relatively large quadratic (second-order) NLO responses. $\mathrm{Ru}^{\mathrm{II}}$ complexes of the tris(1pyrazolyl)methane (Tpm) ligand have been studied quite extensively, ${ }^{10}$ and using such a ligand which most commonly coordinates in a tridentate, facial manner offers possibilities for binding various other ligands in a mutually cis orientation. The present study involves a series of new $\mathrm{Ru}{ }^{\mathrm{II}} \mathrm{Cl}(\mathrm{Tpm})$ complexes with two pyridine or pyridyl coligands. The optical spectroscopic, electrochemical and NLO properties of two of these new species are compared 
with those of their cis- $\left\{\mathrm{Ru}^{\mathrm{II}}\left(\mathrm{NH}_{3}\right)_{4}\right\}^{2+}$ analogues, and several X-ray crystallographic studies are presented. 


\section{Experimental Section}

Materials and Procedures. The compounds Tpm, ${ }^{11} \mathrm{Ru}^{\mathrm{II}} \mathrm{Cl}_{3}(\mathrm{Tpm}) \cdot 1.5 \mathrm{H}_{2} \mathrm{O},{ }^{12}$ $\left[\mathrm{Ru}^{\mathrm{II}} \mathrm{Cl}_{2}(\mathrm{Tpm})(\mathrm{NO})\right] \mathrm{PF}_{6}{ }^{13} \mathrm{~N}$-methyl-4,4'-bipyridinium hexafluorophosphate $\left(\left[\mathrm{MeQ}^{+}\right] \mathrm{PF}_{6}\right)^{14}$ and $N$-phenyl-4,4'-bipyridinium chloride $\left(\left[\mathrm{PhQ}^{+}\right] \mathrm{Cl} \cdot 2 \mathrm{H}_{2} \mathrm{O}\right)^{15}$ were synthesized by following previously published methods. Tpm was recrystallized from boiling water to give white needle-like crystals in yields of ca. $70 \%$. All other reagents were obtained commercially and used as supplied. Products were dried overnight in a vacuum desiccator (silica gel) prior to any characterization and were heated under vacuum at ca. $100{ }^{\circ} \mathrm{C}$ before $\mathrm{CHN}$ analyses.

General Physical Measurements. ${ }^{1} \mathrm{H}$ NMR spectra were recorded on Bruker AV400 or DPX-300 spectrometers, with all shifts referenced to residual solvent signals and quoted with respect to TMS. The $\mathrm{AA}^{\prime} \mathrm{BB}^{\prime}$ patterns of pyridyl or phenyl rings are reported as simple doublets, with ' $J$ values' referring to the two most intense peaks. Elemental analyses were performed by the Microanalytical Laboratory, University of Manchester and UV-vis spectra were obtained by using a Shimadzu UV-2401 PC spectrophotometer. IR spectroscopy was performed on solid samples by using an Excalibur BioRad FT-IR spectrometer, and mass spectra were recorded by using +electrospray on a Micromass Platform II spectrometer. Cyclic voltammetric measurements were performed by using an Ivium CompactStat. A single-compartment cell was used with a silver/silver chloride reference electrode $(3 \mathrm{M} \mathrm{NaCl}$, saturated $\mathrm{AgCl}$ ) separated by a salt bridge from a glassy-carbon $2 \mathrm{~mm}$ disk working electrode and Pt wire auxiliary electrode. Acetonitrile was used as supplied from Sigma-Aldrich (HPLC grade), and $\left[\mathrm{N}\left(\mathrm{C}_{4} \mathrm{H}_{9}-n\right)_{4}\right] \mathrm{PF}_{6}$ (Fluka, electrochemical grade) was used as the supporting electrolyte. Solutions containing ca. $10^{-3} \mathrm{M}$ analyte $\left(0.1 \mathrm{M}\left[\mathrm{N}\left(\mathrm{C}_{4} \mathrm{H}_{9}-n\right)_{4}\right] \mathrm{PF}_{6}\right)$ were deaerated by purging with $\mathrm{N}_{2}$. All $E_{1 / 2}$ values were calculated from $\left(E_{\mathrm{pa}}+E_{\mathrm{pc}}\right) / 2$ at a scan rate of $100 \mathrm{mV} \mathrm{s}^{-1}$.

Synthesis of $\left[\mathbf{R u}^{\mathrm{II}} \mathbf{C l}(\mathbf{T p m})(\mathbf{p y})_{2}\right] \mathbf{P F}_{\mathbf{6}}(\mathbf{1}) .\left[\mathrm{Ru}^{\mathrm{II}} \mathrm{Cl}_{2}(\mathrm{Tpm})(\mathrm{NO})\right] \mathrm{PF}_{6}(113 \mathrm{mg}, 0.201$ mmol), $\mathrm{NaN}_{3}(13.4 \mathrm{mg}, 0.206 \mathrm{mmol})$, pyridine $(0.8 \mathrm{~mL})$ and methanol $(8 \mathrm{~mL})$ were stirred under Ar for $1.5 \mathrm{~h}$. During this time, the brown suspension became lighter in color. The mixture was then heated at reflux for $1 \mathrm{~h}$, to give a clear dark yellow solution. After cooling 
to room temperature, a few crystals of $\mathrm{NH}_{4} \mathrm{PF}_{6}$ were added and volatiles were removed under vacuum. The resulting brown oil was dissolved in acetone and filtered through a mixture of $\mathrm{MgSO}_{4}$ and celite, removing the $\mathrm{NaCl}$ by-product. The acetone was removed under vacuum, then the sticky brown solid was dissolved in dry dichloromethane and diethyl ether added slowly to give a precipitate; this was filtered off, washed with diethyl ether and dried to give a yellow solid: $100 \mathrm{mg}, 73 \%$; $\delta_{\mathrm{H}}\left(\left(\mathrm{CD}_{3}\right)_{2} \mathrm{CO}, 400 \mathrm{MHz}\right) 9.79(1 \mathrm{H}, \mathrm{s}, \mathrm{CH}), 8.78-8.76(5 \mathrm{H}$, $\left.\mathrm{C}_{3} \mathrm{H}_{3} \mathrm{~N}_{2}+\mathrm{pyH}^{2,6}\right), 8.60\left(2 \mathrm{H}, \mathrm{d}, J=2.8 \mathrm{~Hz}, \mathrm{C}_{3} \mathrm{H}_{3} \mathrm{~N}_{2}\right), 8.01\left(1 \mathrm{H}, \mathrm{d}, J=2.3 \mathrm{~Hz}, \mathrm{C}_{3} \mathrm{H}_{3} \mathrm{~N}_{2}\right), 7.93$ $\left(2 \mathrm{H}, \mathrm{t}, J=7.6 \mathrm{~Hz}, \mathrm{pyH}^{4}\right), 7.76\left(2 \mathrm{H}, \mathrm{d}, J=2.2 \mathrm{~Hz}, \mathrm{C}_{3} \mathrm{H}_{3} \mathrm{~N}_{2}\right), 7.44\left(4 \mathrm{H}, \mathrm{t}, J=7.1 \mathrm{~Hz}, \mathrm{pyH}^{3,5}\right)$, $6.77\left(1 \mathrm{H}, \mathrm{t}, J=2.6 \mathrm{~Hz}, \mathrm{C}_{3} \mathrm{H}_{3} \mathrm{~N}_{2}-\mathrm{H}^{4}\right), 6.61\left(2 \mathrm{H}, \mathrm{t}, J=2.6 \mathrm{~Hz}, \mathrm{C}_{3} \mathrm{H}_{3} \mathrm{~N}_{2}-\mathrm{H}^{4}\right)$. Anal. Calcd (\%) for $\mathrm{C}_{20} \mathrm{H}_{20} \mathrm{ClF}_{6} \mathrm{~N}_{8} \mathrm{PRu} \cdot 1.5 \mathrm{H}_{2} \mathrm{O}: \mathrm{C}, 35.3 ; \mathrm{H}, 3.4 ; \mathrm{N}, 16.5$. Found: $\mathrm{C}, 35.4 ; \mathrm{H}, 3.0 ; \mathrm{N}, 16.1 . \mathrm{m} / z$ $=509\left[\left(\mathrm{M}-\mathrm{PF}_{6}\right)^{+}\right]$. Single crystals suitable for X-ray diffraction studies were grown by slow diffusion of diethyl ether vapor into an acetone solution at room temperature.

Synthesis of $\left[\mathbf{R u}^{\mathrm{II}} \mathbf{C l}(\mathbf{T p m})(\mathbf{E I N})_{2}\right] \mathbf{P F}_{\mathbf{6}}$ (2). $\left[\mathrm{Ru}^{\mathrm{II}} \mathrm{Cl}_{2}(\mathrm{Tpm})(\mathrm{NO})\right] \mathrm{PF}_{6}(111 \mathrm{mg}, 0.198$ mmol), $\mathrm{NaN}_{3}(12.7 \mathrm{mg}, 0.195 \mathrm{mmol})$, ethyl isonicotinate (EIN, $\left.1.0 \mathrm{~mL}\right)$ and methanol (12 $\mathrm{mL}$ ) were stirred under Ar for $1 \mathrm{~h}$. During this time, the brown suspension became lighter in color and acquired an orange tint. The mixture was then heated at reflux for $1 \mathrm{~h}$, to give a clear, intensely orange solution. After cooling to room temperature, the volatiles were removed under vacuum. The resulting orange oil was dissolved in acetone $(5 \mathrm{~mL})$, and a few crystals of $\mathrm{NH}_{4} \mathrm{PF}_{6}$ were added. The $\mathrm{NaCl}$ by-product was removed by filtration through celite, adding further acetone $(10 \mathrm{~mL})$. The orange solution was concentrated to $2 \mathrm{~mL}$ and diethyl ether $(20 \mathrm{~mL})$ was added. The turbid mixture was stored in a refrigerator overnight, then the orange precipitate was filtered off, washed with diethyl ether and dried: $100 \mathrm{mg}$, 64\%; $\delta_{\mathrm{H}}\left(\left(\mathrm{CD}_{3}\right)_{2} \mathrm{CO}, 300 \mathrm{MHz}\right) 9.91(1 \mathrm{H}, \mathrm{s}, \mathrm{CH}), 8.99\left(4 \mathrm{H}, \mathrm{d}, J=6.8 \mathrm{~Hz}, \mathrm{C}_{5} \mathrm{H}_{4} \mathrm{~N}\right), 8.80(1$ $\left.\mathrm{H}, \mathrm{d}, J=3.0 \mathrm{~Hz}, \mathrm{C}_{3} \mathrm{H}_{3} \mathrm{~N}_{2}\right), 8.64\left(2 \mathrm{H}, \mathrm{d}, J=2.8 \mathrm{~Hz}, \mathrm{C}_{3} \mathrm{H}_{3} \mathrm{~N}_{2}\right), 8.03(1 \mathrm{H}, \mathrm{d}, J=2.3 \mathrm{~Hz}$, $\left.\mathrm{C}_{3} \mathrm{H}_{3} \mathrm{~N}_{2}\right), 7.85\left(4 \mathrm{H}, \mathrm{d}, J=6.8 \mathrm{~Hz}, \mathrm{C}_{5} \mathrm{H}_{4} \mathrm{~N}\right), 7.80\left(2 \mathrm{H}, \mathrm{d}, J=2.2 \mathrm{~Hz}, \mathrm{C}_{3} \mathrm{H}_{3} \mathrm{~N}_{2}\right), 6.80(1 \mathrm{H}, \mathrm{t}, J$ $\left.=2.6 \mathrm{~Hz}, \mathrm{C}_{3} \mathrm{H}_{3} \mathrm{~N}_{2}-\mathrm{H}^{4}\right), 6.64\left(2 \mathrm{H}, \mathrm{t}, J=2.6 \mathrm{~Hz}, \mathrm{C}_{3} \mathrm{H}_{3} \mathrm{~N}_{2}-\mathrm{H}^{4}\right), 4.42\left(4 \mathrm{H}, \mathrm{q}, J=7.1 \mathrm{~Hz}, \mathrm{CH}_{2}\right)$, $1.37(6 \mathrm{H}, \mathrm{t}, J=7.1 \mathrm{~Hz}, \mathrm{Me}) \cdot v(\mathrm{C}=\mathrm{O}) 1716 \mathrm{~s} \mathrm{~cm}^{-1}, v(\mathrm{C}-\mathrm{O}) 1277 \mathrm{~cm}^{-1}$. Anal. Calcd (\%) for $\mathrm{C}_{26} \mathrm{H}_{28} \mathrm{ClF}_{6} \mathrm{~N}_{8} \mathrm{O}_{4} \mathrm{PRu}: \mathrm{C}, 39.1 ; \mathrm{H}, 3.5 ; \mathrm{N}, 14.0$. Found: $\mathrm{C}, 38.8 ; \mathrm{H}, 3.1 ; \mathrm{N}, 14.0 . \mathrm{m} / z=653$ 
$\left[\left(\mathrm{M}-\mathrm{PF}_{6}\right)^{+}\right]$. Single crystals suitable for X-ray diffraction studies were grown by slow diffusion of diethyl ether vapor into a methanol solution at room temperature.

Synthesis of $\left[\mathbf{R u}^{\mathrm{II}} \mathbf{C l}(\mathbf{T p m})\left(\mathrm{MeQ}^{+}\right)_{2}\right]\left[\mathbf{P F}_{6}\right]_{3}$ (3). $\left[\mathrm{Ru}^{\mathrm{II}} \mathrm{Cl}_{2}(\mathrm{Tpm})(\mathrm{NO})\right] \mathrm{PF}_{6}(110 \mathrm{mg}$, $0.196 \mathrm{mmol}), \mathrm{NaN}_{3}(12.9 \mathrm{mg}, 0.198 \mathrm{mmol}),\left[\mathrm{MeQ}^{+}\right] \mathrm{PF}_{6}(130 \mathrm{mg}, 0.411 \mathrm{mmol})$ and methanol $(15 \mathrm{~mL})$ were stirred under Ar for $1 \mathrm{~h}$. During this time, the brown suspension became lighter in color, changing to light purple, then dark purple. The mixture was heated at reflux for $1 \mathrm{~h}$, with no further color change. The solvent was removed under vacuum, the purple residue dissolved in acetone $\left(10 \mathrm{~mL}\right.$ ), and solid $\mathrm{NH}_{4} \mathrm{PF}_{6}$ (ca. $0.1 \mathrm{~g}$ ) added. The purple solution was concentrated to $2 \mathrm{~mL}$ and diethyl ether $(25 \mathrm{~mL})$ was added. The turbid mixture was stored in a refrigerator for $1.5 \mathrm{~h}$, then the dark purple precipitate was filtered off. This material was dissolved in acetone $(20 \mathrm{~mL})$, and the solution filtered through celite. The filtrate was concentrated to $2 \mathrm{~mL}$ and the crude product precipitated with diethyl ether, filtered off, washed with diethyl ether and dried. Purification was effected by using a basic alumina column, eluting with $0.05 \mathrm{M} \mathrm{NH}_{4} \mathrm{PF}_{6}$ in acetonitrile. The second, purple fraction was collected and evaporated to dryness, then reprecipitated from acetone/diethyl ether to yield a dark purple solid: $98 \mathrm{mg}, 44 \%$; $\delta_{\mathrm{H}}\left(\left(\mathrm{CD}_{3}\right)_{2} \mathrm{CO}, 400 \mathrm{MHz}\right) 9.89(1 \mathrm{H}, \mathrm{s}, \mathrm{CH}), 9.23(4 \mathrm{H}, \mathrm{d}, J=$ $\left.6.9 \mathrm{~Hz}, \mathrm{C}_{5} \mathrm{H}_{4} \mathrm{~N}\right), 9.08\left(4 \mathrm{H}, \mathrm{d}, J=7.0 \mathrm{~Hz}, \mathrm{C}_{5} \mathrm{H}_{4} \mathrm{~N}\right), 8.80\left(1 \mathrm{H}, \mathrm{d}, J=2.5 \mathrm{~Hz}, \mathrm{C}_{3} \mathrm{H}_{3} \mathrm{~N}_{2}\right), 8.67(4$ $\left.\mathrm{H}, \mathrm{d}, J=7.0 \mathrm{~Hz}, \mathrm{C}_{5} \mathrm{H}_{4} \mathrm{~N}\right), 8.65\left(2 \mathrm{H}, \mathrm{d}, J=3.0 \mathrm{~Hz}, \mathrm{C}_{3} \mathrm{H}_{3} \mathrm{~N}_{2}\right), 8.06(1 \mathrm{H}, \mathrm{d}, J=2.3 \mathrm{~Hz}$, $\left.\mathrm{C}_{3} \mathrm{H}_{3} \mathrm{~N}_{2}\right), 8.03\left(4 \mathrm{H}, \mathrm{d}, J=7.0 \mathrm{~Hz}, \mathrm{C}_{5} \mathrm{H}_{4} \mathrm{~N}\right), 7.82\left(2 \mathrm{H}, \mathrm{d}, J=2.2 \mathrm{~Hz}, \mathrm{C}_{3} \mathrm{H}_{3} \mathrm{~N}_{2}\right), 6.81(1 \mathrm{H}, \mathrm{t}, J$ $\left.=2.6 \mathrm{~Hz}, \mathrm{C}_{3} \mathrm{H}_{3} \mathrm{~N}_{2}-\mathrm{H}^{4}\right), 6.66\left(2 \mathrm{H}, \mathrm{t}, J=2.6 \mathrm{~Hz}, \mathrm{C}_{3} \mathrm{H}_{3} \mathrm{~N}_{2}-\mathrm{H}^{4}\right), 4.65(6 \mathrm{H}, \mathrm{s}, \mathrm{Me})$. Anal. Calcd (\%) for $\mathrm{C}_{32} \mathrm{H}_{32} \mathrm{ClF}_{18} \mathrm{~N}_{10} \mathrm{P}_{3} \mathrm{Ru}: \mathrm{C}, 34.1 ; \mathrm{H}, 2.9 ; \mathrm{N}, 12.4$. Found: $\mathrm{C}, 33.7 ; \mathrm{H}, 2.9 ; \mathrm{N}, 12.2 . \mathrm{m} / z=$ $983\left[\left(\mathrm{M}-\mathrm{PF}_{6}\right)^{+}\right], 419\left[\left(\mathrm{M}-2 \mathrm{PF}_{6}\right)^{2+}\right]$. Single crystals suitable for X-ray diffraction studies were grown by slow diffusion of diethyl ether vapor into an acetone solution at room temperature.

Synthesis of $\left[\mathbf{R u}^{\mathrm{II}} \mathbf{C l}(\mathbf{T p m})\left(\mathrm{PhQ}^{+}\right)_{2}\right]\left[\mathbf{P F}_{\mathbf{6}}\right]_{\mathbf{3}}(\mathbf{4}) . \mathrm{Ru}^{\mathrm{II}} \mathrm{Cl}_{3}(\mathrm{Tpm}) \cdot 1.5 \mathrm{H}_{2} \mathrm{O}(82 \mathrm{mg}, 0.183$ $\mathrm{mmol})$ and $\left[\mathrm{PhQ}^{+}\right] \mathrm{Cl} \cdot 2 \mathrm{H}_{2} \mathrm{O}(307 \mathrm{mg}, 1.01 \mathrm{mmol})$ in $1: 1$ ethanol/water (degassed, $40 \mathrm{~mL}$ ) were heated at reflux under Ar for $14 \mathrm{~h}$. The initial brown suspension became blue-purple as the temperature increased. After cooling to room temperature, the volume was reduced under 
vacuum to ca. $10 \mathrm{~mL}$ and saturated aqueous $\mathrm{NH}_{4} \mathrm{PF}_{6}(5 \mathrm{~mL})$ was added. A dark purple, sticky precipitate formed immediately. Acetone was added, and the solution was filtered through celite $/ \mathrm{MgSO}_{4}$, removing insoluble white material. The filtrate was concentrated to 3-4 mL, diethyl ether added, and the dark purple solid filtered off and dried. Purification was effected as for 3 to yield a dark purple solid: $97 \mathrm{mg}, 41 \%$; $\delta_{\mathrm{H}}\left(\left(\mathrm{CD}_{3}\right)_{2} \mathrm{CO}, 400 \mathrm{MHz}\right) 9.86(1 \mathrm{H}$, s, $\mathrm{CH}), 9.53\left(4 \mathrm{H}, \mathrm{d}, J=7.0 \mathrm{~Hz}, \mathrm{C}_{5} \mathrm{H}_{4} \mathrm{~N}\right), 9.15\left(4 \mathrm{H}, \mathrm{d}, J=7.0 \mathrm{~Hz}, \mathrm{C}_{5} \mathrm{H}_{4} \mathrm{~N}\right), 8.85(4 \mathrm{H}, \mathrm{d}, J=7.0$ $\left.\mathrm{Hz}, \mathrm{C}_{5} \mathrm{H}_{4} \mathrm{~N}\right), 8.81\left(1 \mathrm{H}, \mathrm{d}, J=2.9 \mathrm{~Hz}, \mathrm{C}_{3} \mathrm{H}_{3} \mathrm{~N}_{2}\right), 8.66\left(2 \mathrm{H}, \mathrm{d}, J=2.8 \mathrm{~Hz}, \mathrm{C}_{3} \mathrm{H}_{3} \mathrm{~N}_{2}\right), 8.13(4 \mathrm{H}$, $\left.\mathrm{d}, J=7.0 \mathrm{~Hz}, \mathrm{C}_{5} \mathrm{H}_{4} \mathrm{~N}\right), 8.09\left(1 \mathrm{H}, \mathrm{d}, J=2.2 \mathrm{~Hz}, \mathrm{C}_{3} \mathrm{H}_{3} \mathrm{~N}_{2}\right), 8.01-7.98(4 \mathrm{H}, \mathrm{Ph}), 7.84-7.81(8$ $\left.\mathrm{H}, \mathrm{C}_{3} \mathrm{H}_{3} \mathrm{~N}_{2}+\mathrm{Ph}\right), 6.83\left(1 \mathrm{H}, \mathrm{t}, J=2.6 \mathrm{~Hz}, \mathrm{C}_{3} \mathrm{H}_{3} \mathrm{~N}_{2}-\mathrm{H}^{4}\right), 6.68\left(2 \mathrm{H}, \mathrm{t}, J=2.6 \mathrm{~Hz}, \mathrm{C}_{3} \mathrm{H}_{3} \mathrm{~N}_{2}-\mathrm{H}^{4}\right)$. Anal. Calcd (\%) for $\mathrm{C}_{42} \mathrm{H}_{36} \mathrm{ClF}_{18} \mathrm{~N}_{10} \mathrm{P}_{3} \mathrm{Ru} \cdot 3 \mathrm{H}_{2} \mathrm{O}: \mathrm{C}, 38.6 ; \mathrm{H}, 3.2 ; \mathrm{N}, 10.7$. Found: $\mathrm{C}, 38.1 ; \mathrm{H}$, 2.4; $\mathrm{N}, 10.6 . m / z=1107\left[\left(\mathrm{M}-\mathrm{PF}_{6}\right)^{+}\right], 480\left[\left(\mathrm{M}-2 \mathrm{PF}_{6}\right)^{2+}\right]$.

X-Ray Structural Determinations. The data were collected on a Bruker APEX CCD $\mathrm{X}$-ray diffractometer by using graphite-monochromated, MoK $\alpha$ radiation (wavelength $=$ $0.71073 \AA$ ). Data processing was carried out by using the Bruker SAINT $^{16}$ software package and a semi-empirical absorption correction was applied by using SADABS. ${ }^{16}$ The structures were solved by direct methods and refined by full-matrix least-squares on all $F_{0}{ }^{2}$ data using SHELXS-9 $7^{17}$ and SHELXL-97. ${ }^{18}$ All non-H atoms were refined anisotropically, with H atoms bonded to $\mathrm{C}$ or $\mathrm{N}$ included in calculated positions by using the riding method; those bonded to the water $\mathrm{O}$ atoms could not be located. All other calculations were carried out by using the SHELXTL package. ${ }^{19}$ Static disorder is shown by the $\mathrm{PF}_{6}{ }^{-}$anion in $\mathbf{2}$, and by the acetone solvent molecule in $\mathbf{3} \cdot \mathrm{Me}_{2} \mathrm{CO}$. Crystallographic data and refinement details are presented in Table 1. 
Table 1. Crystallographic Data and Refinement Details for Salts $\mathbf{1} \cdot \mathrm{Me}_{2} \mathrm{CO}, \mathbf{2}$ and $\mathbf{3} \cdot \mathrm{Me}_{2} \mathrm{CO}$

\begin{tabular}{|c|c|c|c|}
\hline & $\mathbf{1} \cdot \mathrm{Me}_{2} \mathrm{CO}$ & 2 & $\mathbf{3} \cdot \mathrm{Me}_{2} \mathrm{CO}$ \\
\hline empirical formula & $\mathrm{C}_{23} \mathrm{H}_{26} \mathrm{ClF}_{6} \mathrm{~N}_{8} \mathrm{OPRu}$ & $\mathrm{C}_{26} \mathrm{H}_{28} \mathrm{ClF}_{6} \mathrm{~N}_{8} \mathrm{O}_{4} \mathrm{PRu}$ & $\mathrm{C}_{35} \mathrm{H}_{38} \mathrm{ClF}_{18} \mathrm{~N}_{10} \mathrm{OP}_{3} \mathrm{Ru}$ \\
\hline $\mathrm{fw}$ & 712.01 & 798.05 & 1186.18 \\
\hline cryst system & Monoclinic & Monoclinic & Monoclinic \\
\hline space group & $P 2_{1} / n$ & $P 2_{1} / n$ & $P 2_{1} / c$ \\
\hline space group number & 14 & 14 & 14 \\
\hline$a / \AA$ & $11.491(2)$ & $16.2895(14)$ & $22.7148(19)$ \\
\hline$b / \AA$ & $8.5395(17)$ & $7.7203(7)$ & $11.6324(10)$ \\
\hline$c / \AA$ & $28.167(6)$ & $26.279(2)$ & $17.5531(15)$ \\
\hline$\alpha / \operatorname{deg}$ & & & \\
\hline$\beta / \operatorname{deg}$ & $97.888(4)$ & $104.064(2)$ & $108.045(2)$ \\
\hline$\gamma / \mathrm{deg}$ & & & \\
\hline$U / \AA^{3}$ & $2737.7(9)$ & $3205.8(5)$ & $4409.9(6)$ \\
\hline$Z$ & 4 & 4 & 4 \\
\hline$T / \mathrm{K}$ & $100(2)$ & $100(2)$ & $100(2)$ \\
\hline$\mu / \mathrm{mm}^{-1}$ & 0.805 & 0.704 & 0.647 \\
\hline cryst size/mm & $0.20 \times 0.10 \times 0.05$ & $0.18 \times 0.08 \times 0.02$ & $0.20 \times 0.12 \times 0.08$ \\
\hline cryst description & yellow plate & amber plate & purple block \\
\hline reflns collected & 19005 & 22347 & 37416 \\
\hline $\begin{array}{l}\text { independent reflns } \\
\left(R_{\text {int }}\right)\end{array}$ & $4828(0.1035)$ & $5672(0.0940)$ & $10350(0.0915)$ \\
\hline $\begin{array}{l}\theta_{\text {max }} / \text { deg } \\
\text { (completeness) }\end{array}$ & $25.03(99.9)$ & $25.00(99.9)$ & $25.00(99.8)$ \\
\hline reflns with $I>2 \sigma(I)$ & 3023 & 4319 & 5534 \\
\hline GOF on $F^{2}$ & 0.923 & 1.282 & 0.885 \\
\hline $\begin{array}{l}\text { final } R 1, w R 2[I> \\
2 \sigma(I)]\end{array}$ & $0.0554,0.0754$ & $0.0871,0.1776$ & $0.0585,0.1080$ \\
\hline (all data) & $0.1129,0.0887$ & $0.1212,0.2022$ & $0.1245,0.1236$ \\
\hline peak and hole/e $\AA^{-3}$ & $0.788,-0.767$ & $1.141,-1.331$ & $1.114,-0.865$ \\
\hline
\end{tabular}

Hyper-Rayleigh Scattering. The apparatus and experimental procedures used for the fs HRS studies were exactly as described previously. ${ }^{20}$ All measurements were carried out in acetonitrile with crystal violet as an external reference (octupolar $\beta_{x x x, 800}=500 \times 10^{-30}$ esu in acetonitrile; from the value of $340 \times 10^{-30}$ esu in methanol, corrected for local field factors at optical frequencies), and using the $800 \mathrm{~nm}$ fundamental of a regenerative mode-locked $\mathrm{Ti}^{3+}$ :sapphire laser (Spectra Physics, model Tsunami ${ }^{\circledR}, 100$ fs pulses, $1 \mathrm{~W}, 80 \mathrm{MHz}$ ). Dilute solutions $\left(10^{-5}-10^{-6} \mathrm{M}\right)$ were used to ensure a linear dependence of $I_{2 \mathrm{\sigma}} / I_{\mathrm{\omega}}^{2}$ on concentration, precluding the need for Lambert-Beer correction factors. An absence of demodulation at 800 $\mathrm{nm}$, i.e. constant values of $\beta$ versus frequency, confirmed that no luminescence contributions to the HRS signals were present at $400 \mathrm{~nm}$. The reported $\beta$ values are the averages taken 
from measurements at different amplitude modulation frequencies. The $\beta_{800}$ data shown are based on the assumption of a single $\beta$ component, $\beta_{z z z}$, and are derived from the total HRS intensity $\left\langle\beta_{H R S}^{2}\right\rangle$ by using eq 1 .

$$
\left\langle\beta_{H R S}^{2}\right\rangle=\left(\frac{1}{7}+\frac{1}{35}\right) \beta_{800}^{2}
$$

Unfortunately, due to the use of very low concentrations and the relatively low signal intensities obtained, it was not possible to measure HRS depolarization ratios $^{21}$ for the new compounds.

Stark Spectroscopy. The Stark apparatus, experimental methods and data collection procedure were as previously reported, ${ }^{22}$ except that a Xe arc lamp was used as the light source instead of a W filament bulb. The Stark spectrum for each compound was measured at least twice. The data analysis was carried out as previously described, ${ }^{22}$ by using the zeroth, first and second derivatives of the absorption spectrum for analysis of the Stark $\Delta \varepsilon(v)$ spectrum in terms of the Liptay treatment. ${ }^{23}$ The dipole-moment change, $\Delta \mu_{12}=\mu_{\mathrm{e}}-\mu_{\mathrm{g}}$, where $\mu_{\mathrm{e}}$ and $\mu_{\mathrm{g}}$ are the respective excited and ground-state dipole moments, was then calculated from the coefficient of the second derivative component. Butyronitrile was used as the glassing medium, for which the local field correction $f_{\text {int }}$ is estimated as $1.33 .^{22}$ A twostate analysis of the ICT transitions gives

$$
\Delta \mu_{\mathrm{ab}}^{2}=\Delta \mu_{12}^{2}+4 \mu_{12}^{2}
$$

where $\Delta \mu_{\mathrm{ab}}$ is the dipole-moment change between the diabatic states and $\Delta \mu_{12}$ is the observed (adiabatic) dipole-moment change. The value of the transition dipole-moment $\mu_{12}$ can be determined from the oscillator strength $f_{\text {os }}$ of the transition by

$$
\left|\mu_{12}\right|=\left(\frac{f_{\mathrm{os}}}{1.08 \times 10^{-5} E_{\max }}\right)^{1 / 2}
$$


where $E_{\max }$ is the energy of the ICT maximum (in wavenumbers) and $\mu_{12}$ is in e $\AA$. The latter is converted into Debye units on multiplying by 4.803 . The degree of delocalization $c_{\mathrm{b}}{ }^{2}$ and electronic coupling matrix element $H_{\mathrm{ab}}$ for the diabatic states are given by

$$
\begin{array}{r}
\mathrm{c}_{\mathrm{b}}^{2}=\frac{1}{2}\left[1-\left(\frac{\Delta \mu_{12}^{2}}{\Delta \mu_{12}^{2}+4 \mu_{12}^{2}}\right)^{1 / 2}\right] \\
\left|H_{\mathrm{ab}}\right|=\left|\frac{E_{\max }\left(\mu_{12}\right)}{\Delta \mu_{\mathrm{ab}}}\right|
\end{array}
$$

If the hyperpolarizability $\beta_{0}$ tensor has only nonzero elements along the ICT direction, then this quantity is given by

$$
\beta_{0}=\frac{3 \Delta \mu_{12}\left(\mu_{12}\right)^{2}}{\left(E_{\max }\right)^{2}}
$$

A relative error of $\pm 20 \%$ is estimated for the $\beta_{0}$ values derived from the Stark data and using eq 5, while experimental errors of $\pm 10 \%$ are estimated for $\mu_{12}, \Delta \mu_{12}$ and $\Delta \mu_{\mathrm{ab}}, \pm 15 \%$ for $H_{\mathrm{ab}}$ and $\pm 50 \%$ for $c_{\mathrm{b}}{ }^{2}$. Note that the $\pm 20 \%$ uncertainty for the $\beta_{0}$ values is merely statistical and does not account for any errors introduced by two-state extrapolation.

Theoretical Calculations. Geometry optimizations (in the gas phase only), density functional theory (DFT) and time-dependent DFT (TD-DFT) calculations were undertaken by using the Gaussian 09 software. ${ }^{24}$ Studies were performed by using the functionals B $86,{ }^{25}$ B3LYP $,{ }^{26} \mathrm{CAM}-\mathrm{B} 3 \mathrm{LYP},{ }^{27} \mathrm{PBE}^{2} \mathrm{PBE}^{28}$ or $\mathrm{M} 06,{ }^{29}$ with various basis sets. The complexes in the $\mathrm{PF}_{6}{ }^{-}$salts $\mathbf{1}-\mathbf{4}$ are denoted $\mathbf{1}^{\prime}-\mathbf{4}^{\prime}$. For the monocationic complexes $\mathbf{1}^{\prime}$ and $\mathbf{2}^{\prime}$, the best simulations of the experimental UV-vis spectra are obtained with B3LYP and the LANL2DZ ${ }^{30}$ basis set for Ru with 6-311G* for $\mathrm{C}, \mathrm{N}$ and $\mathrm{O}$; 6-311G for $\mathrm{H}$ and $6-311+\mathrm{G}^{*}$ for $\mathrm{Cl}$. In contrast, the spectra of the tricationic complexes $\mathbf{3}^{\prime}$ and $\mathbf{4}^{\prime}$ are best modeled with the PBE1PBE functional with the same basis set combination. Using these parameters and the conductor-like polarizable continuum model $(\mathrm{CPCM})^{31}$ of acetonitrile, the first 50 excited 
singlet states were calculated via TD-DFT. UV-vis spectra in the range $200-800 \mathrm{~nm}$ were simulated by using the GaussSum program ${ }^{32}$ (curve fwhm $=3000 \mathrm{~cm}^{-1}$ ).

$\beta_{0}$ values were calculated by using B3LYP (for $\mathbf{2}^{\prime}$ only) or PBE1PBE (for $\mathbf{2}^{\prime}-\mathbf{4}^{\prime}$ ), as the analytical second derivatives of the dipole moment with respect to an external electric field. The LANL2DZ/6-311G/6-311G*/6-311+G* mixed basis set was used, and calculations were run both in the gas phase and in $\mathrm{MeCN}$ solvent. The calculated $\beta_{\text {tot }}$ value is the overall magnitude of the static first hyperpolarizability related to the individual tensor components according to ${ }^{33}$

$$
\beta_{\text {tot }}=\left[\left(\beta_{x x x}+\beta_{x y y}+\beta_{x z z}\right)^{2}+\left(\beta_{y y y}+\beta_{y z z}+\beta_{y x x}\right)^{2}+\left(\beta_{z z z}+\beta_{z x x}+\beta_{z y y}\right)^{2}\right]^{\frac{1}{2}}
$$

and

$$
\beta_{\text {tot }}=\left(\beta_{x}^{2}+\beta_{y}^{2}+\beta_{z}^{2}\right)^{\frac{1}{2}}
$$

For the complexes studied here with $C_{\text {s }}$ point group symmetry, Gaussian 09 assigns the plane of symmetry as $y z$, with the $y$ axis directed between the pyridine/pyridyl ligands but offset somewhat from the $C_{3}$ axis of the $\mathrm{Ru}$ (II $(\mathrm{Tpm})$ unit (as shown in Figure 1). 


\section{Results and Discussion}
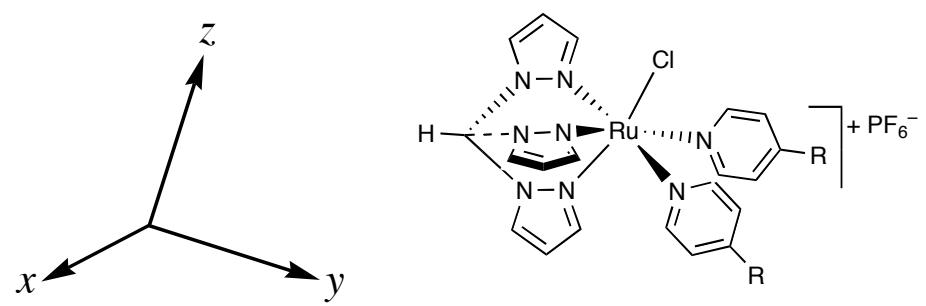

$\mathrm{R}=\mathrm{H}(\mathbf{1}), \mathrm{CO}_{2} \mathrm{Et}(2)$
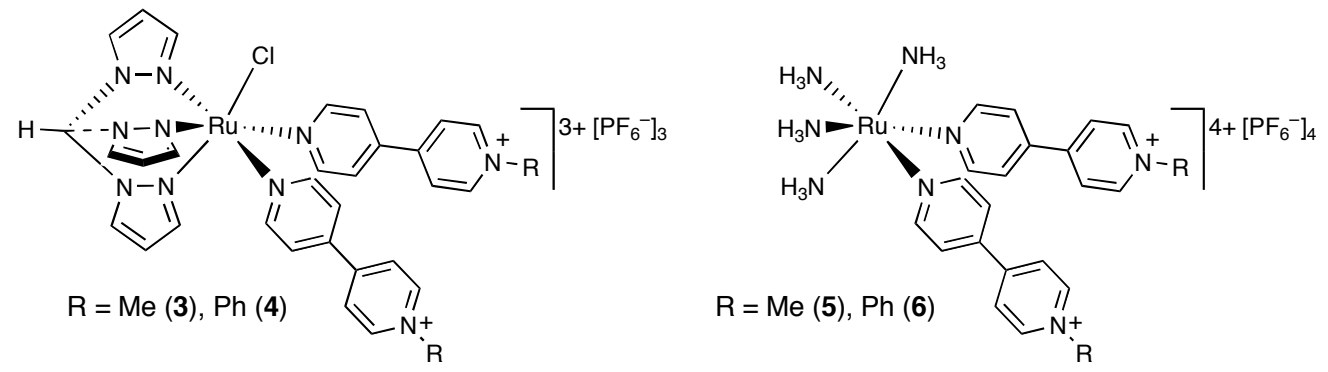

Figure 1. Chemical structures of the new $\mathrm{Ru}^{\mathrm{II}}$ complex salts investigated, together with related previously reported $c i s-\left\{\mathrm{Ru}^{\mathrm{II}}\left(\mathrm{NH}_{3}\right)_{4}\right\}^{2+}$ species. $^{9 \mathrm{a}}$ The axes shown approximate to those used in the theoretical studies.

Synthesis. The new complex salts 1-3 were prepared from reactions of the precursor $\left[\mathrm{Ru}^{\mathrm{II}} \mathrm{Cl}_{2}(\mathrm{Tpm})(\mathrm{NO})\right] \mathrm{PF}_{6}{ }^{13}$ in methanol. As in other studies, the linearly-coordinated nitrosyl ligand is labilized selectively via nucleophilic attack by azide anion, ${ }^{34}$ and one of the chloride ligands is substituted also. Substitution of the remaining chloride occurs much less readily, minimizing the formation of unwanted tris-pyridyl derivatives. $\mathbf{1}$ and $\mathbf{2}$ were obtained in reasonably good yields and pure form relatively readily. However, column chromatography on basic alumina with significant sacrifice of product was required in order to isolate pure 3 . Using the same method for $\mathbf{4}$ did not afford a sufficiently pure material, so this complex was instead prepared from $\mathrm{Ru}^{\mathrm{II}} \mathrm{Cl}_{3}(\mathrm{Tpm}) \cdot 1.5 \mathrm{H}_{2} \mathrm{O}^{12}$ in $1: 1$ ethanol/water, followed by chromatographic purification as for 3. Initial experiments using silica gel as the column support resulted in decomposition of the complexes. It is worth noting that the mono-MeQ ${ }^{+}$ complex salts $\left[\mathrm{Ru}^{\mathrm{II}}(\mathrm{Tpm})(\mathrm{L})\left(\mathrm{MeQ}^{+}\right)\right]\left[\mathrm{PF}_{6}\right]_{3} \quad\left[\mathrm{~L}=2,2^{\prime}\right.$-bipyridyl or 4-methyl-4'- $(N-$ phenothiazylmethyl)-2,2'-bipyridyl] have been studied for their photoexcitation properties by Meyer and colleagues. ${ }^{10 \mathrm{c}}$ 
Electronic Spectroscopy. The electronic absorption spectra of the new complex salts 1-4 were recorded in acetonitrile and the results are presented in Table 2, together with data reported previously for $\mathbf{5}$ and $\mathbf{6}^{9 \mathrm{a}}$ for comparison purposes. Representative spectra of 1-4 are shown in Figure 2. Each of the new complexes shows a single intense, broad absorption band in the visible region, which can be ascribed $\mathrm{d}\left(\mathrm{Ru}^{\mathrm{II}}\right) \rightarrow \pi^{*}\left(\mathrm{~L}^{\mathrm{A}}\right)\left(\mathrm{L}^{\mathrm{A}}=\mathrm{EIN}, \mathrm{MeQ}^{+}\right.$or $\left.\mathrm{PhQ}^{+}\right)$ MLCT character. Additional high-energy bands in the UV region are due to intraligand $\pi \rightarrow$ $\pi^{*}$ excitations.

Table 2. UV-Vis and Electrochemical Data for Complex Salts 1-6 in Acetonitrile

\begin{tabular}{|c|c|c|c|c|c|}
\hline \multirow[t]{2}{*}{$\begin{array}{l}\text { complex } \\
\text { salt }\end{array}$} & \multirow[t]{2}{*}{$\begin{array}{l}\lambda_{\max }, \mathrm{nm}^{a} \\
\left(\varepsilon, 10^{3} \mathrm{M}^{-1} \mathrm{~cm}^{-1}\right)\end{array}$} & \multirow[t]{2}{*}{$\begin{array}{l}E_{\max } \\
(\mathrm{eV})\end{array}$} & \multirow[t]{2}{*}{ assignment } & \multicolumn{2}{|c|}{$\begin{array}{c}E_{1 / 2}, \mathrm{~V} \text { vs } \mathrm{Ag}-\mathrm{AgCl} \\
\left(\Delta E_{\mathrm{p}}, \mathrm{mV}\right)^{b}\end{array}$} \\
\hline & & & & $\mathrm{Ru}^{\mathrm{III} / I I}$ & $\mathrm{~L}^{\mathrm{A}}$ reductions \\
\hline \multirow[t]{3}{*}{1} & $365(13.6)$ & 3.40 & $\mathrm{~d} \rightarrow \pi^{*}(\mathrm{py})$ & 0.80 & \\
\hline & $282 \mathrm{sh}(4.1)$ & 4.40 & $\mathrm{~d} \rightarrow \pi^{*}(\mathrm{Tpm})$ & $(80)$ & \\
\hline & $246(7.4)$ & 5.04 & $\pi \rightarrow \pi^{*}$ & & \\
\hline \multirow[t]{4}{*}{2} & $423(14.0)$ & 2.93 & $\mathrm{~d} \rightarrow \pi^{*}(\mathrm{EIN})$ & 0.90 & $-1.48(70)$ \\
\hline & $328 \mathrm{sh}(4.7)$ & 3.78 & $\mathrm{~d} \rightarrow \pi^{*}(\mathrm{EIN})$ & $(70)$ & $-1.62(70)$ \\
\hline & $293 \mathrm{sh}(5.2)$ & 4.23 & $\mathrm{~d} \rightarrow \pi^{*}(\mathrm{Tpm})$ & & \\
\hline & $266(9.1)$ & 4.66 & $\pi \rightarrow \pi^{*}$ & & \\
\hline \multirow[t]{3}{*}{3} & $499(12.5)$ & 2.48 & $\mathrm{~d} \rightarrow \pi^{*}\left(\mathrm{MeQ}^{+}\right)$ & 0.91 & $-0.84(140)$ \\
\hline & $333 \operatorname{sh}(6.4)$ & 3.72 & $\mathrm{~d} \rightarrow \pi^{*}(\mathrm{Tpm})$ & $(60)$ & $-1.50(130)$ \\
\hline & $263(42.3)$ & 4.71 & $\pi \rightarrow \pi^{*}$ & & \\
\hline \multirow[t]{2}{*}{4} & $525(18.3)$ & 2.36 & $\mathrm{~d} \rightarrow \pi^{*}\left(\mathrm{PhQ}^{+}\right)$ & 0.93 & $-0.62(100)$ \\
\hline & $284(40.4)$ & 4.37 & $\pi \rightarrow \pi^{*}$ & $(70)$ & $-1.29(180)$ \\
\hline \multirow[t]{3}{*}{$5^{c}$} & $570(17.5)$ & 2.18 & $\mathrm{~d} \rightarrow \pi^{*}\left(\mathrm{MeQ}^{+}\right)$ & 0.79 & $-0.81(110)$ \\
\hline & $502(15.1)$ & 2.47 & $\mathrm{~d} \rightarrow \pi^{*}\left(\mathrm{MeQ}^{+}\right)$ & $(85)$ & $-1.42(65)$ \\
\hline & $262(33.3)$ & 4.73 & $\pi \rightarrow \pi^{*}$ & & $-1.55(70)$ \\
\hline \multirow[t]{3}{*}{$6^{c}$} & $606(20.4)$ & 2.05 & $\mathrm{~d} \rightarrow \pi^{*}\left(\mathrm{PhQ}^{+}\right)$ & 0.79 & $-0.66(110)$ \\
\hline & $528(16.5)$ & 2.35 & $\mathrm{~d} \rightarrow \pi^{*}\left(\mathrm{PhQ}^{+}\right)$ & $(70)$ & $-1.26(70)$ \\
\hline & $284(31.2)$ & 4.37 & $\pi \rightarrow \pi^{*}$ & & $-1.38(65)$ \\
\hline
\end{tabular}

${ }^{a}$ Solutions ca. $1-7 \times 10^{-5}$ M. ${ }^{b}$ Measured in solutions ca. $10^{-3} \mathrm{M}$ in analyte and $0.1 \mathrm{M}$ in $\left[\mathrm{N}\left(\mathrm{C}_{4} \mathrm{H}_{9}-n\right)_{4}\right] \mathrm{PF}_{6}$ at a $2 \mathrm{~mm}$ disk glassy carbon (1-4) or Pt (5 and 6) working electrode with a scan rate of $100 \mathrm{mV} \mathrm{s}^{-1}(\mathbf{1}-\mathbf{4})$ or $200 \mathrm{mV} \mathrm{s}^{-1}$ (5 and 6). Ferrocene internal reference $E_{1 / 2}=$ $0.44 \mathrm{~V}, \Delta E_{\mathrm{p}}=70 \mathrm{mV} .{ }^{c}$ Data taken from ref $9 \mathrm{a}$.

The MLCT band shows a trend of steady red-shifting on moving along the series $\mathbf{1} \rightarrow$ 4 (Figure 2), consistent with an expected increasing electron acceptor strength of $\mathrm{L}^{\mathrm{A}}$. The band intensities are similar for 1-3, but a little larger for $\mathbf{4}$. The previously reported compounds $\mathbf{5}$ and $\mathbf{6}$ show MLCT bands with two distinct maxima, ${ }^{9 a}$ while the related $\mathbf{3}$ and $\mathbf{4}$ 
display very broad bands with only one, quite poorly defined maximum. However, TD-DFT calculations (see below) confirm the expectation that multiple transitions contribute to these bands. It is probably coincidental that the maxima estimated for $\mathbf{3}$ and $\mathbf{4}$ correspond closely with the respective high energy maxima for $\mathbf{5}$ and $\mathbf{6}$. The fact that the latter show also MLCT transitions to significantly lower energies indicates that a cis- $\left\{\mathrm{Ru}^{\mathrm{II}}\left(\mathrm{NH}_{3}\right)_{4}\right\}^{2+}$ center is more strongly electron-donating than a $\left\{\mathrm{Ru}^{\mathrm{II}} \mathrm{Cl}(\mathrm{Tpm})\right\}^{+}$moiety. The constant positions of the UV bands on replacing the Tpm and chloride with four ammonia ligands indicates that these absorptions are associated with the $\mathrm{MeQ}^{+} / \mathrm{PhQ}^{+}$ligands primarily, the weaker bands due to Tpm being masked in $\mathbf{3}$ and $\mathbf{4}$.

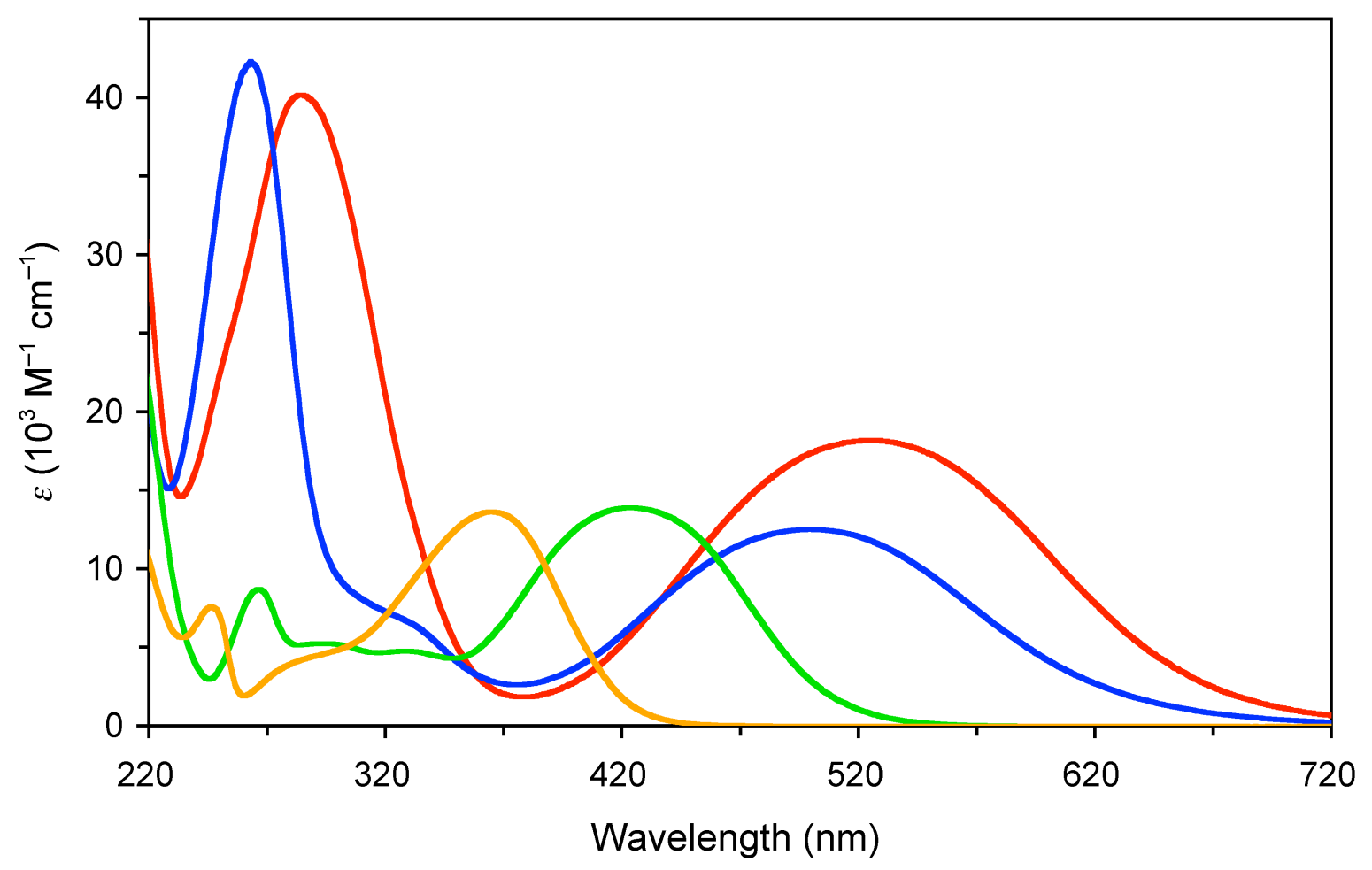

Figure 2. UV-vis absorption spectra of the complex salts 1 (gold), 2 (green), 3 (blue) and 4 (red) in acetonitrile at $293 \mathrm{~K}$.

Electrochemistry. The complex salts 1-4 were studied by cyclic voltammetry in acetonitrile and the results are presented in Table 2, together with data reported previously for 5 and 6. ${ }^{9 a}$ Representative voltammograms of 1-4 are shown in Figure 3. All of the new complexes show reversible $\mathrm{Ru}^{\mathrm{III} / \mathrm{II}}$ oxidation waves, together with two or more $\mathrm{L}^{\mathrm{A}}$-based 
reduction processes for $2-\mathbf{4}$ that are quasireversible or irreversible. All of these complexes therefore have potential to behave as redox-switchable NLO chromophores. ${ }^{35}$

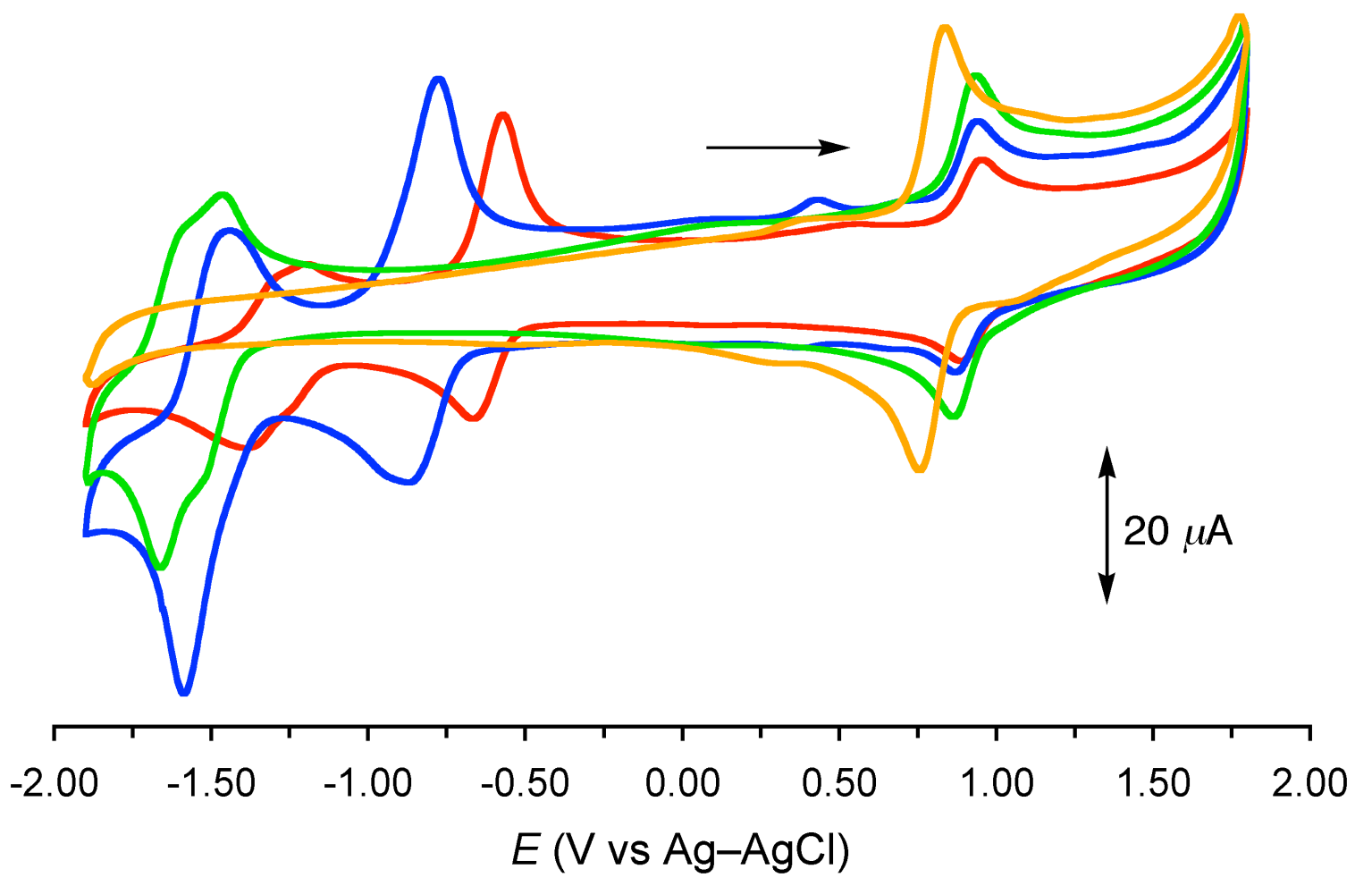

Figure 3. Cyclic voltammograms of the complex salts 1 (gold), 2 (green), 3 (blue) and 4 (red) recorded at $100 \mathrm{mV} \mathrm{s}^{-1}$ in acetonitrile $\left(0.1 \mathrm{M}\right.$ in $\left.\left[\mathrm{N}\left(\mathrm{C}_{4} \mathrm{H}_{9}-n\right)_{4}\right] \mathrm{PF}_{6}\right)$ with a glassy carbon working electrode. The concentrations are variable in order to decrease overlap between the traces, and the single-headed arrow indicates the direction of the initial scans.

Complex salt 2 shows two overlapping $\mathrm{L}^{\mathrm{A}}$-based reduction waves (Figure 3) that are well resolved by differential pulse measurements. By analogy with $\mathbf{5}$ and $\mathbf{6},{ }^{\text {a }}$ the reduction waves for $\mathbf{3}$ and $\mathbf{4}$ are expected to correspond with two-electron processes (for the two ligands becoming reduced at very similar potentials), but differential pulse experiments did not resolve these. The $\mathrm{Ru}^{\mathrm{III} / \mathrm{II}}$ potential increases by $100 \mathrm{mV}$ on moving from $\mathbf{1}$ to $\mathbf{2}$, attributable to the electron-withdrawing influence of the two ester substituents. On moving along the series to $\mathbf{3}$, then $\mathbf{4}$, the $\mathrm{Ru}^{\mathrm{III} / \mathrm{II}}$ waves show only small further anodic shifts, indicating that the energy of the Ru-based HOMO is affected only slightly by changing the 4substituent on the pyridyl ligands. The stronger electron-accepting ability of $\mathrm{PhQ}^{+}$as opposed 
to $\mathrm{MeQ}^{+}$, noted previously, ${ }^{9 \mathrm{a}, 36,37}$ increases the potentials for $\mathrm{L}^{\mathrm{A}}$-based reductions on moving from 3 to 4 (Figure 3).

Comparing the data for $\mathbf{3}$ and $\mathbf{4}$ with those for $\mathbf{5}$ and $\mathbf{6}$ reveals that the $\mathrm{Ru}{ }^{\mathrm{III} / \mathrm{II}}$ potentials decrease by $120-140 \mathrm{mV}$ when ammonia ligands replace Tpm and chloride (Table 2). This observation is consistent with the corresponding decreases in the MLCT energies (see above). As expected, the $\mathrm{L}^{\mathrm{A}}$-based reduction waves are comparatively less sensitive to changes in the coligands, with (inconsistent) changes of only $30-40 \mathrm{mV}$ for the $E_{1 / 2}$ value of the first wave on moving from $\mathbf{3}$ to $\mathbf{5}$ or from $\mathbf{4}$ to $\mathbf{6}$.

Crystallography. Single crystal X-ray structures have been obtained for the complex salts $\mathbf{1} \cdot \mathrm{Me}_{2} \mathrm{CO}, \mathbf{2}$ and $\mathbf{3} \cdot \mathrm{Me}_{2} \mathrm{CO}$. Representations of the molecular structures are shown in Figures 4-6, and selected interatomic distances and angles are presented in Table 3.

Table 3. Selected Interatomic Distances $(\AA)$ and Angles (deg) for the Complex Salts $\mathbf{1} \cdot \mathrm{Me}_{2} \mathrm{CO}, \mathbf{2}$ and $\mathbf{3} \cdot \mathrm{Me}_{2} \mathrm{CO}$

\begin{tabular}{llll}
\hline & $\mathbf{1 \cdot M e _ { 2 } \mathrm { CO }}$ & $\mathbf{2}$ & $\mathbf{3} \mathrm{Me}_{2} \mathrm{CO}$ \\
\hline $\mathrm{Ru}-\mathrm{Cl}$ & $2.398(2)$ & $2.386(2)$ & $2.403(1)$ \\
$\mathrm{Ru}-\mathrm{N}\left(\mathrm{L}^{\mathrm{A}}\right)$ & $2.067(5)$ & $2.100(7)$ & $2.100(4)$ \\
$\mathrm{Ru}-\mathrm{N}\left(\mathrm{L}^{\mathrm{A}}\right)$ & $2.084(5)$ & $2.085(7)$ & $2.077(4)$ \\
$\mathrm{Ru}-\mathrm{N}(\mathrm{Tpm}$, trans-Cl) & $2.084(5)$ & $2.022(8)$ & $2.033(4)$ \\
$\mathrm{Ru}-\mathrm{N}\left(\mathrm{Tpm}\right.$, trans-L $\left.^{\mathrm{A}}\right)$ & $2.048(5)$ & $2.054(7)$ & $2.050(4)$ \\
$\mathrm{Ru}-\mathrm{N}\left(\mathrm{Tpm}\right.$, trans-L $\left.^{\mathrm{A}}\right)$ & $2.082(4)$ & $2.051(7)$ & $2.055(4)$ \\
$\mathrm{Cl}-\mathrm{Ru}-\mathrm{N}\left(\mathrm{L}^{\mathrm{A}}\right)$ & $90.1(1)$ & $91.7(2)$ & $91.2(1)$ \\
$\mathrm{Cl}-\mathrm{Ru}-\mathrm{N}\left(\mathrm{L}^{\mathrm{A}}\right)$ & $90.1(1)$ & $90.6(2)$ & $91.1(1)$ \\
$\mathrm{Cl}-\mathrm{Ru}-\mathrm{N}(\mathrm{Tpm})$ & $94.5(2)$ & $91.5(2)$ & $89.7(1)$ \\
$\mathrm{Cl}-\mathrm{Ru}-\mathrm{N}(\mathrm{Tpm})$ & $90.1(1)$ & $89.6(2)$ & $89.7(1)$ \\
$\mathrm{Cl}-\mathrm{Ru}-\mathrm{N}(\mathrm{Tpm})$ & $173.9(1)$ & $175.9(2)$ & $173.8(1)$ \\
$\mathrm{N}\left(\mathrm{L}^{\mathrm{A}}\right)-\mathrm{Ru}-\mathrm{N}\left(\mathrm{L}^{\mathrm{A}}\right)$ & $89.4(2)$ & $95.5(3)$ & $95.7(2)$ \\
$\mathrm{N}\left(\mathrm{L}^{\mathrm{A}}\right)-\mathrm{Ru}-\mathrm{N}(\mathrm{Tpm})$ & $176.1(2)$ & $174.6(3)$ & $174.2(2)$ \\
$\mathrm{N}\left(\mathrm{L}^{\mathrm{A}}\right)-\mathrm{Ru}-\mathrm{N}(\mathrm{Tpm})$ & $90.6(2)$ & $89.0(3)$ & $87.6(2)$ \\
$\mathrm{N}\left(\mathrm{L}^{\mathrm{A}}\right)-\mathrm{Ru}-\mathrm{N}(\mathrm{Tpm})$ & $93.5(2)$ & $91.8(3)$ & $93.6(2)$ \\
$\mathrm{N}\left(\mathrm{L}^{\mathrm{A}}\right)-\mathrm{Ru}-\mathrm{N}(\mathrm{Tpm})$ & $94.5(2)$ & $89.7(3)$ & $93.6(2)$ \\
$\mathrm{N}\left(\mathrm{L}^{\mathrm{A}}\right)-\mathrm{Ru}-\mathrm{N}(\mathrm{Tpm})$ & $179.8(2)$ & $174.9(3)$ & $176.6(2)$ \\
$\mathrm{N}\left(\mathrm{L}^{\mathrm{A}}\right)-\mathrm{Ru}-\mathrm{N}(\mathrm{Tpm})$ & $94.9(2)$ & $91.1(3)$ & $90.0(2)$ \\
$\mathrm{N}(\mathrm{Tpm})-\mathrm{Ru}-\mathrm{N}(\mathrm{Tpm})$ & $85.5(2)$ & $85.7(3)$ & $86.7(2)$ \\
$\mathrm{N}(\mathrm{Tpm})-\mathrm{Ru}-\mathrm{N}(\mathrm{Tpm})$ & $86.5(2)$ & $86.8(3)$ & $86.7(2)$ \\
$\mathrm{N}(\mathrm{Tpm})-\mathrm{Ru}-\mathrm{N}(\mathrm{Tpm})$ & $85.0(2)$ & $86.5(3)$ & $85.1(2)$ \\
\hline
\end{tabular}




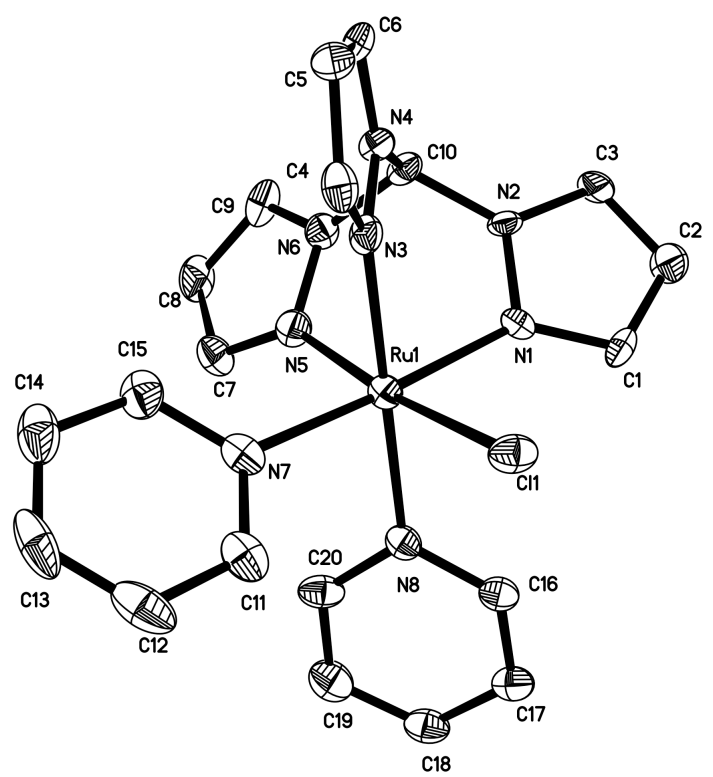

Figure 4. Representation of the molecular structure of the complex cation in the salt 1 $\bullet \mathrm{Me}_{2} \mathrm{CO}$, with the $\mathrm{PF}_{6}{ }^{-}$anion, acetone molecule and $\mathrm{H}$ atoms removed for clarity $(50 \%$ probability ellipsoids).

The structures reveal the expected tridentate, facially coordinating mode of the Tpm ligand. Each of the complexes adopts a slightly distorted octahedral geometry, with N(Tpm)$\mathrm{Ru}-\mathrm{N}(\mathrm{Tpm})$ angles of ca. $85-87^{\circ}$, and small deviations from the ideal 90 or $180^{\circ}$ in most of the other angles (Table 3 ). The structure of the complex in $\mathbf{1} \cdot \mathrm{Me}_{2} \mathrm{CO}$ resembles closely that reported for $\left[\mathrm{Ru}^{\mathrm{II}}(\mathrm{Tpm})(\mathrm{py})_{3}\right]\left[\mathrm{PF}_{6}\right]_{2}{ }^{38}$ In $\mathbf{2}$ and $\mathbf{3} \cdot \mathrm{Me}_{2} \mathrm{CO}$, the $\mathrm{Ru}-\mathrm{N}(\mathrm{Tpm})$ distances are shorter than the $\mathrm{Ru}-\mathrm{N}\left(\mathrm{L}^{\mathrm{A}}\right)$ distances by ca. $0.04-0.08 \AA$, while this is not the case for 1• $\mathrm{Me}_{2} \mathrm{CO}$. Also, while the $\mathrm{Ru}-\mathrm{N}(\mathrm{Tpm})$ distances trans to the $\mathrm{L}^{\mathrm{A}}$ ligands are slightly longer than those trans to the chloride ligand in $\mathbf{2}$ and $\mathbf{3} \cdot \mathrm{Me}_{2} \mathrm{CO}$, such an apparent structural trans effect is not observed in $\mathbf{1} \cdot \mathrm{Me}_{2} \mathrm{CO}$. 


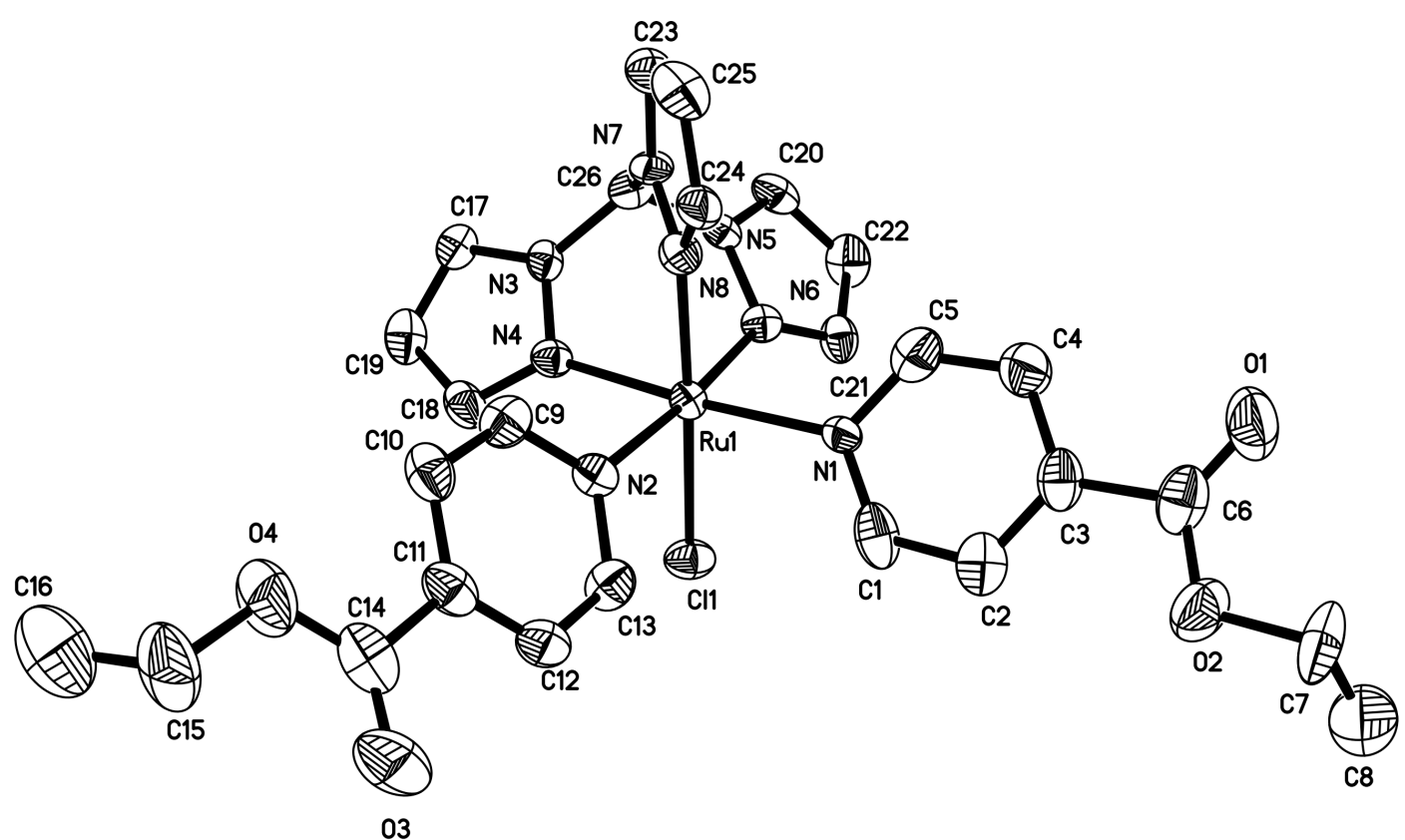

Figure 5. Representation of the molecular structure of the complex cation in the salt $\mathbf{2}$, with the $\mathrm{PF}_{6}{ }^{-}$anion and $\mathrm{H}$ atoms removed for clarity (50\% probability ellipsoids).

In $1 \cdot \mathrm{Me}_{2} \mathrm{CO}$, the dihedral angles formed between the planes of the py ligands and their opposite pyrazolyl (pyz) rings are very different, being 12.6 and $89.0^{\circ}$. In contrast, the angles between the pyridyl and trans pyz rings in $\mathbf{2}$ are both small and closely similar (7.0 and $\left.9.0^{\circ}\right)$. An intermediate degree of variation is found in $3 \cdot \mathrm{Me}_{2} \mathrm{CO}$, with corresponding angles of 8.7 and $25.5^{\circ}$. The dihedral angles between the two pyridyl rings within the $\mathrm{MeQ}^{+}$ ligands in $3 \cdot \mathrm{Me}_{2} \mathrm{CO}$ are both $25.3^{\circ}$, similar to those observed in related complexes previously. $^{9 b, 34 \mathrm{e}}$ While various $\mathrm{Ru}^{\mathrm{II}}(\mathrm{Tpm})$ complexes have been structurally characterized, ${ }^{10 \mathrm{~b}, \mathrm{~d}-\mathrm{q}, \mathrm{s}, 38} 2$ appears to be only the second $\mathrm{Ru}{ }^{\mathrm{II}}$ complex of the EIN ligand for which crystallographic data are available, following trans- $(\mathrm{Cl}, \mathrm{CO})(\mathrm{P}, \mathrm{P})-$ $\mathrm{Ru}^{\mathrm{II}} \mathrm{Cl}\left(\mathrm{CH}=\mathrm{CH}^{n} \mathrm{Bu}\right)\left(\mathrm{PPh}_{3}\right)_{2}(\mathrm{EIN})(\mathrm{CO}){ }^{39}$ The ester substituents in 2 lie almost coplanar with the pyridyl rings, forming dihedral angles of 6.4 and $9.1^{\circ}$, the latter being identical to that observed in trans- $(\mathrm{Cl}, \mathrm{CO})(\mathrm{P}, \mathrm{P})-\mathrm{Ru}^{\mathrm{II}} \mathrm{Cl}\left(\mathrm{CH}=\mathrm{CH}^{n} \mathrm{Bu}\right)\left(\mathrm{PPh}_{3}\right)_{2}(\mathrm{EIN})(\mathrm{CO}){ }^{39}$ All of $\mathbf{1} \mathrm{Me}_{2} \mathrm{CO}, 2$ and $3 \cdot \mathrm{Me}_{2} \mathrm{CO}$ adopt centrosymmetric packing structures, so none of these materials is expected to show significant quadratic NLO effects. 


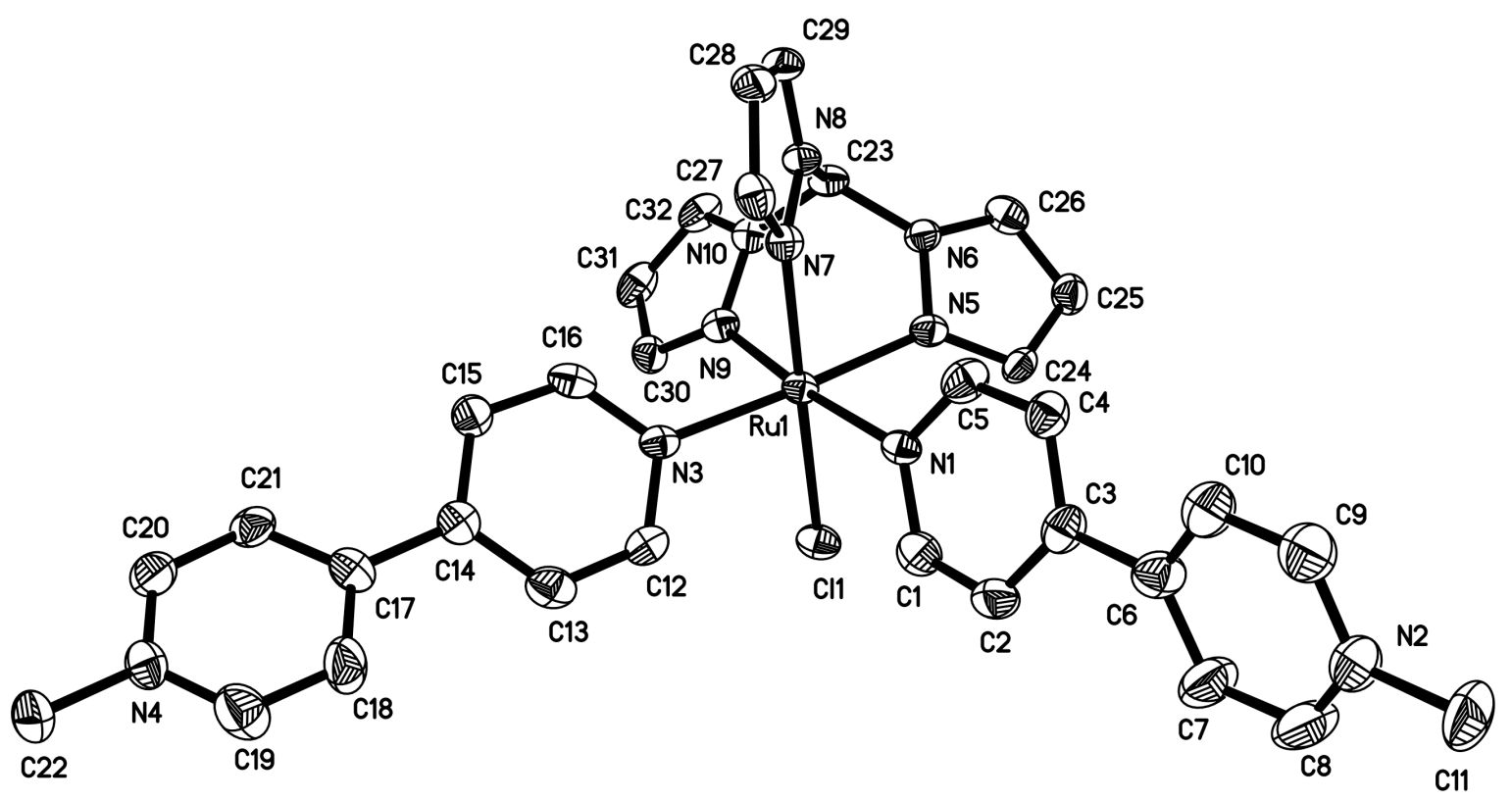

Figure 6. Representation of the molecular structure of the complex cation in the salt 3• $\mathrm{Me}_{2} \mathrm{CO}$, with the $\mathrm{PF}_{6}{ }^{-}$anions, acetone molecule and $\mathrm{H}$ atoms removed for clarity $(50 \%$ probability ellipsoids).

Table 4. Visible Absorption and HRS Data for Complex Salts 2-6 in Acetonitrile

\begin{tabular}{llll}
\hline \multirow{2}{*}{ complex salt } & $\begin{array}{l}\lambda_{\max }, \mathrm{nm}^{a} \\
\left(\varepsilon, 10^{3} \mathrm{M}^{-1} \mathrm{~cm}^{-1}\right)\end{array}$ & $\sqrt{\left\langle\beta_{H R S}^{2}\right\rangle^{b}}$ & $\beta_{800}{ }^{c}$ \\
\cline { 3 - 4 } & & \multicolumn{2}{c}{$\left(10^{-30} \mathrm{esu}\right)$} \\
\hline $\mathbf{2}$ & $423(14.0)$ & $29 \pm 3$ & $71 \pm 7$ \\
$\mathbf{3}$ & $499(12.5)$ & $40 \pm 5$ & $96 \pm 11$ \\
$\mathbf{4}$ & $525(18.3)$ & $35 \pm 4$ & $84 \pm 9$ \\
$\mathbf{5}^{d}$ & $570(17.5)$ & $58 \pm 9$ & $139 \pm 21$ \\
& $502(15.1)$ & & \\
$\mathbf{6}^{d}$ & $606(20.4)$ & $53 \pm 8$ & $127 \pm 19$ \\
& $528(16.5)$ & & \\
\hline
\end{tabular}

${ }^{a}$ Solutions ca. $1-7 \times 10^{-5}$ M. ${ }^{b}$ The total molecular HRS response without any assumption of symmetry or contributing tensor elements, measured by using an $800 \mathrm{~nm} \mathrm{Ti}^{3+}$ :sapphire laser. The quoted cgs units (esu) can be converted into SI units $\left(\mathrm{C}^{3} \mathrm{~m}^{3} \mathrm{~J}^{-2}\right)$ by dividing by a factor of $2.693 \times 10^{20}$, or into atomic units $(\mathrm{au})$ by dividing by $0.8640 \times 10^{-32}$. ${ }^{c}$ First hyperpolarizability derived by assuming a single major tensor component. ${ }^{d}$ Data taken from ref 9a.

Hyper-Rayleigh Scattering. The $\beta$ values of complex salts $2-\mathbf{4}$ have been measured in acetonitrile solutions by using the HRS technique with a $800 \mathrm{~nm} \operatorname{laser}^{20}$ and the results are 
collected in Table 4, together with the data published previously for 5 and $6 .{ }^{9 a} \mathbf{1}$ did not give a significant HRS signal, consistent with its relatively high energy absorption bands (see above) being associated with only a small NLO response. The fundamental wavelength was chosen because none of the complexes absorbs significantly at $800 \mathrm{~nm}$, and only 2 absorbs relatively strongly at the second harmonic (SH) of $400 \mathrm{~nm}$ (Figure 2).

The $\beta_{800}$ values obtained for $\mathbf{5}$ and $\mathbf{6}$ are surprising in not showing an increase in the NLO response as the electron-accepting strength of the pyridinium units increases. ${ }^{9 a}$ These data contrast with the results of earlier $1064 \mathrm{~nm}$ HRS studies on 1D dipolar $\mathrm{Ru}^{\mathrm{II}}$ ammine complexes, which always show substantial increases in $\beta_{0}$ on replacing a Me with $\mathrm{Ph} N$ substituent. ${ }^{15,37,40}$ It is noteworthy that the HRS data for the new compounds $\mathbf{3}$ and $\mathbf{4}$ are reminiscent of those for 5 and $\mathbf{6}$ (Table 4), showing responses that are not significantly different. The significant increases in $\beta_{800}$ on moving from $\mathbf{3}$ to $\mathbf{5}$ or from $\mathbf{4}$ to $\mathbf{6}$ are consistent with the stronger electron-donating power of a cis- $\left\{\mathrm{Ru}^{\mathrm{II}}\left(\mathrm{NH}_{3}\right)_{4}\right\}^{2+}$ as opposed to a $\left\{\mathrm{Ru}^{\mathrm{II}} \mathrm{Cl}(\mathrm{Tpm})\right\}^{+}$moiety, indicated by the MLCT absorption and $\mathrm{Ru}^{\mathrm{III} / \mathrm{II}}$ potentials (see above). While caution should be exercised when comparing $\beta$ values that are uncorrected for resonance, the extent of absorption at 800 and $400 \mathrm{~nm}$ is similar, and relatively low for all of 3-6. The $\beta_{800}$ value for $\mathbf{2}$ is a little smaller than that of $\mathbf{3}$, indicating an actually considerable decrease for the complex with shorter $\mathrm{L}^{\mathrm{A}}$ ligands, masked by strong resonance enhancement at $400 \mathrm{~nm}$.

Although the $\beta_{800}$ data shown are based on the assumption of a single $\beta$ component, $\beta_{z z z}$, the electronic structures and therefore hyperpolarizabilities of these $C_{2 \mathrm{v}}$ symmetric complexes must inevitably show substantial 2D character. However, it was unfortunately not possible to measure HRS depolarization ratios for 2-4 to assess the relative importance of individual $\beta$ tensor components.

Stark Spectroscopy. Complex salts $\mathbf{2}-\mathbf{4}$ have been studied by Stark spectroscopy ${ }^{22,23}$ in butyronitrile glasses at $77 \mathrm{~K}$ and the results are shown in Table 5, together with the data reported already for $\mathbf{5}$ and $\mathbf{6} .{ }^{9 \mathrm{a}} \mathbf{1}$ was not studied because it lacks a visible absorption band, and the operational cut-off of our Stark spectrometer is ca. $370 \mathrm{~nm}$. The latter factor also 
means that the ILCT absorptions of 2-6 could not be analyzed, but these high energy transitions are not in any case expected to contribute to the NLO responses substantially.

The absorption spectra for $\mathbf{5}$ and $\mathbf{6}$ were subjected to Gaussian deconvolution in order to allow satisfactory fitting of the Stark data. ${ }^{9 a}$ Representative absorption and electroabsorption spectra for $\mathbf{2 - 4}$ are shown in Figure 7. In contrast to the spectra measured in acetonitrile at $293 \mathrm{~K}$ (Figure 2), the MLCT bands become asymmetric in frozen glasses, but good fits were nonetheless obtained for these new compounds without deconvolution.

2

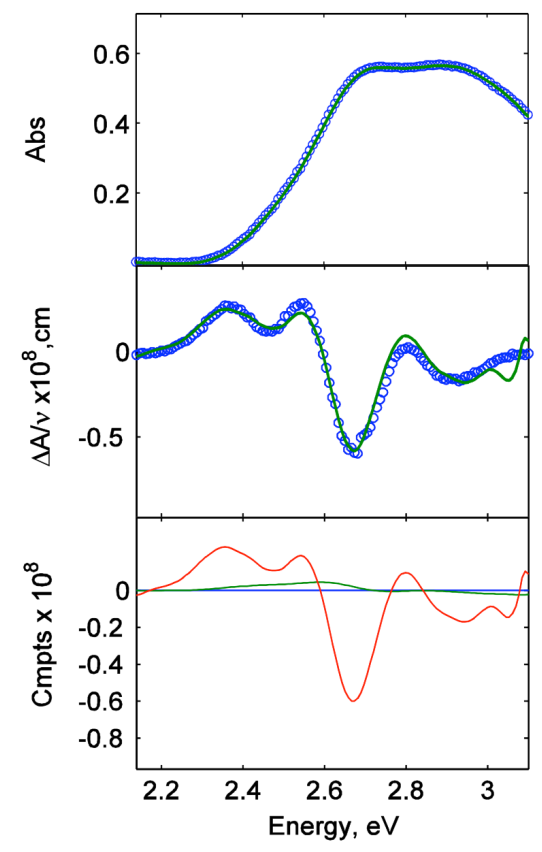

3

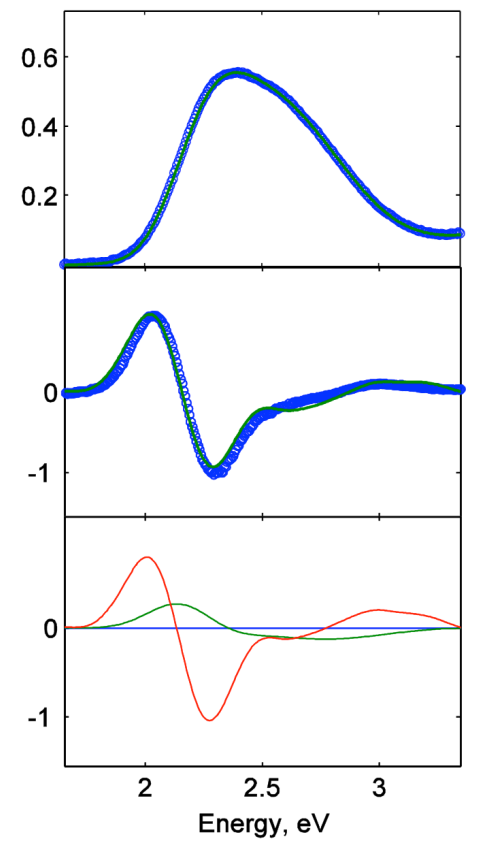

4

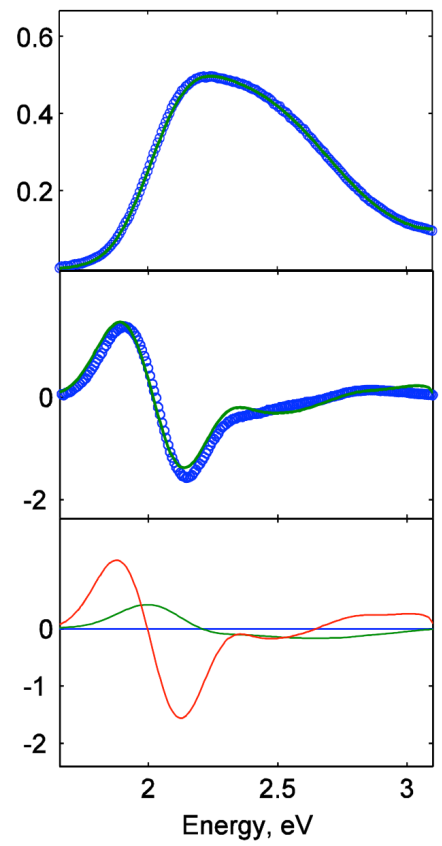

Figure 7. Spectra and calculated fits for the salts 2-4. Top panel: absorption spectrum; middle panel: electroabsorption spectrum, experimental (blue) and fits (green) according to the Liptay equation; ${ }^{23 a}$ bottom panel: contribution of 0 th (blue), 1 st (green) and 2nd (red) derivatives of the absorption spectrum to the calculated fits.

On moving along the series $\mathbf{2} \rightarrow \mathbf{4}$, the MLCT band shows increasing red-shifts of $0.05,0.09$ and $0.12 \mathrm{eV}$ on going from acetonitrile solution to butyronitrile glass (Tables 2 and 5). Such behavior is typical of $\mathrm{Ru}{ }^{\mathrm{II}}$ complex salts. At $77 \mathrm{~K}$, the band intensity increases steadily on moving from 2 to 4 , as shown by the values of $f_{\text {os }}$ and $\mu_{12}$. As expected, the parameters $\Delta \mu_{12}, r_{12}, \Delta \mu_{\mathrm{ab}}$ and $r_{\mathrm{ab}}$ all increase as $\mathrm{L}^{\mathrm{A}}$ becomes larger on moving from 2 to 4 . 
While the degree of delocalization (represented by $c_{b}{ }^{2}$ ) remains essentially constant, the matrix element $H_{\mathrm{ab}}$ that quantifies the strength of $\pi$-electronic coupling decreases as the ligands extend.

We have used the standard two-state $\operatorname{model}^{41}$ (i.e. eq 6, corresponding with the "perturbation series" convention) to estimate $\beta_{0}$ values, and the results are included in Table 5. This approach is clearly only an approximation due to the two-dimensional nature of the chromophores, and the fact that the MLCT bands of 2-4 represent two strongly overlapping transitions. It is worth noting that we have found using a Gaussian deconvolution approach (as for 5 to 6) usually gives total $\beta_{0}$ values similar to those obtained by using direct fitting to the absorption spectra. ${ }^{9 b, 42}$

The $\beta_{0}$ values show a clear trend of increasing by a total of ca. 6 -fold on moving from 2 to 4 . This trend arises from a combination of increasing $\mu_{12}$ and $\Delta \mu_{12}$ values, accompanied by decreasing $E_{\max }$. Notably, a different pattern is shown by the HRS $\beta_{800}$ data (Table 4$)$. The Stark-based $\beta_{0}$ response of $\mathbf{2}$ is relatively modest, in keeping with its short $\pi$-conjugation length and the presence of mildly electron-accepting ester substituents. However, the $\beta_{0}$ values derived for $\mathbf{3}$ and $\mathbf{4}$ are large and similar to those which we obtained for the related $\mathbf{5}$ and 6 by using the same approach previously. ${ }^{9 a}$ As a further comparison, a $\beta_{0}$ value of $236 \times$ $10^{-30}$ esu was determined from Stark data obtained under the same conditions for the benchmark organic salt $\quad(E)-4^{\prime}$-(dimethylamino)- $N$-methyl-4-stilbazolium hexafluorophosphate. ${ }^{42}$ The data for $\mathbf{5}$ and $\mathbf{6}$ do appear to show an increase in $\beta_{0}$ on replacing the $N$-Me with $\mathrm{Ph}$ substituents, but the difference is within the estimated experimental error limits. Also, no clear trend is evident on replacing the chloride and Tpm ligands with $\mathrm{NH}_{3}$, in contrast to the MLCT absorption, electrochemical and HRS data (see above).

Density Functional Theory. In order to rationalise the experimental UV-vis spectra, TD-DFT calculations were performed on the complexes $\mathbf{1}^{\prime}-\mathbf{4}^{\prime}$ by using Gaussian $09^{24}$ Calculated $\mathrm{S}_{0} \rightarrow \mathrm{S}_{1}$ transition energies and the corresponding major orbital contributions are presented in Table 6, and frontier orbital energies in Table 7. The simulated spectra are shown together with those measured in Figures 8 and 10. 
Table 5. Absorption and Stark Spectroscopic Data for Complex Salts 2-6 in Butyronitrile at $77 \mathrm{~K}^{a}$

\begin{tabular}{|c|c|c|c|c|c|c|c|c|c|c|c|}
\hline complex salt & $\begin{array}{r}\lambda_{\max } \\
(\mathrm{nm}) \\
\end{array}$ & $\begin{array}{l}E_{\max } \\
(\mathrm{eV}) \\
\end{array}$ & $f_{\mathrm{os}}{ }^{b}$ & $\begin{array}{l}\mu_{12}^{c} \\
\text { (D) }\end{array}$ & $\begin{array}{l}\Delta \mu_{12}{ }^{d} \\
\text { (D) }\end{array}$ & $\begin{array}{l}\Delta \mu_{\mathrm{ab}}^{e} \\
\text { (D) }\end{array}$ & $\begin{array}{l}r_{12}^{f} \\
(\AA)\end{array}$ & $\begin{array}{l}r_{\mathrm{ab}}{ }^{g} \\
(\AA)\end{array}$ & $c_{\mathrm{b}}^{2 h}$ & $\begin{array}{l}H_{\mathrm{ab}}{ }^{i} \\
\left(10^{3} \mathrm{~cm}^{-1}\right)\end{array}$ & $\begin{array}{l}\beta_{0}{ }^{j} \\
\left(10^{-30} \mathrm{esu}\right)\end{array}$ \\
\hline 2 & 431 & 2.88 & 0.32 & 5.4 & 13.6 & 17.4 & 2.8 & 3.6 & 0.11 & 7.3 & 62 \\
\hline 3 & 518 & 2.39 & 0.44 & 7.0 & 17.5 & 22.5 & 3.7 & 4.7 & 0.11 & 6.0 & 182 \\
\hline \multirow[t]{2}{*}{4} & 554 & 2.24 & 0.62 & 8.6 & 20.7 & 26.9 & 4.3 & 5.6 & 0.12 & 5.8 & 356 \\
\hline & 628 & 1.98 & 0.34 & 6.7 & 10.1 & 16.8 & 2.1 & 3.5 & 0.20 & 6.4 & 137 (199) \\
\hline \multirow[t]{2}{*}{$5^{k}$} & 518 & 2.39 & 0.24 & 5.2 & 11.3 & 15.3 & 2.4 & 3.2 & 0.13 & 6.5 & 62 \\
\hline & 632 & 1.96 & 0.41 & 7.4 & 13.8 & 20.3 & 2.9 & 4.2 & 0.16 & 5.8 & $231(273)$ \\
\hline $6^{k}$ & 512 & 2.42 & 0.20 & 4.6 & 9.9 & 13.5 & 2.1 & 2.8 & 0.13 & 6.7 & 42 \\
\hline
\end{tabular}

${ }^{a}$ The data for 5 and $\mathbf{6}$ are for the two fitted Gaussian components. ${ }^{b}$ For $\mathbf{2 - 4}$, obtained from $\left(4.32 \times 10^{-9} \mathrm{M} \mathrm{cm}^{2}\right) A$ where $A$ is the numerically integrated area under the absorption peak; for 5 and $\mathbf{6}$, obtained from $\left(4.60 \times 10^{-9} \mathrm{M} \mathrm{cm}^{2}\right) \varepsilon_{\max } \times f w_{1 / 2}$ where $\varepsilon_{\max }$ is the maximal molar extinction coefficient and $f w_{1 / 2}$ is the full width at half height (in wavenumbers). ${ }^{c}$ Calculated from eq $3 .{ }^{d}$ Calculated from $f_{\text {int }} \Delta \mu_{12}$ using $f_{\text {int }}=1.33$. ${ }^{e}$ Calculated from eq 2. ${ }^{f}$ Delocalized electron-transfer distance calculated from $\Delta \mu_{12} / e .{ }^{g}$ Effective (localized) electron-transfer distance calculated from $\Delta \mu_{\mathrm{ab}} / e .{ }^{h}$ Calculated from eq $4 .{ }^{i}$ Calculated from eq $5 .{ }^{j}$ Calculated from eq 6 ; the total values are given in brackets for 5 and $6 .{ }^{k}$ Data taken from ref $9 \mathrm{a}$. 
The lowest energy (LE) and most intense band of $\mathbf{1}^{\prime}$ is modeled about three main transitions (Figure 8a) of predominantly HOMO-1 $\rightarrow$ LUMO, HOMO-1 $\rightarrow$ LUMO +1 and HOMO-2 $\rightarrow$ LUMO character (in order of increasing energy). Of the four complexes studied, $\mathbf{1}^{\prime}$ is unique in that numerous weak transitions $\left(f_{\text {os }}<0.05\right)$ in the region $310-375 \mathrm{~nm}$ also contribute to this band. The orbitals involved in the main transitions contained within this band are shown in Figure 9a, while all the other orbitals mentioned in Table 6 are in the Supporting Information (Figure S1). The HOMO, HOMO-1 and HOMO-2 are derived primarily from the $\mathrm{Ru} \mathrm{d}_{\mathrm{yz}}, \mathrm{d}_{\mathrm{xz}}$ and $\mathrm{d}_{\mathrm{x}-\mathrm{y}}{ }^{2}$ orbitals, respectively. Each of these also has a significant $\mathrm{Cl}$ p orbital contribution, while the HOMO and HOMO-1 also feature a minor component from the Tpm $\pi$-orbitals. The LUMO and LUMO +1 both have py $\pi^{*}$ character, and the former exhibits also a significant contribution from the two pyz rings trans to the py ligands. Therefore, the calculations confirm the MLCT assignment of the lowest energy band, but reveal also a minor LLCT component originating from the $\mathrm{Cl}$. The high energy shoulder at ca. $280 \mathrm{~nm}$ (Table 2) is attributable to transitions of largely MLCT character also, but involving $\pi^{*}$-orbitals associated with the Tpm ligand. The LUMO +2 and LUMO +3 are located on the pyz rings trans to the $\mathrm{Cl}^{-}$or py ligands respectively, while $\mathrm{LUMO}+7$ involves all three pyz rings. As expected, the high energy transitions $(\lambda<250 \mathrm{~nm})$ have intraligand, especially py, $\pi \rightarrow \pi^{*}$ character.

The LE band of $\mathbf{2}^{\prime}$ is derived from four main transitions (Figure 8b) of character comparable to those for $\mathbf{1}^{\prime}$. The orbitals involved in the main transitions contained within the LE band for $\mathbf{2}^{\prime}$ are shown in Figure 9b, while all the other orbitals mentioned in Table 6 are in the Supporting Information (Figure S2). The electron-withdrawing ester groups cause the LUMO and LUMO+1 to be stabilised significantly, by 0.84 and $0.86 \mathrm{eV}$, respectively relative to $\mathbf{1}^{\prime}$ (Table 7). The HOMO, HOMO-1 and HOMO-2 show smaller accompanying relative stabilisations of $0.13-0.15 \mathrm{eV}$, as the $\mathrm{Ru}$ center becomes less electron-rich. 
Table 6. Selected TD-DFT-Calculated and Experimental Data for the Complexes $\mathbf{1}^{\prime}-\mathbf{4}^{\prime a}$

\begin{tabular}{|c|c|c|c|c|c|c|}
\hline complex & $\begin{array}{l}\lambda_{\exp }^{b} \\
(\mathrm{~nm})\end{array}$ & $\begin{array}{l}\lambda_{\max }^{c} \\
(\mathrm{~nm})\end{array}$ & $\begin{array}{l}\lambda_{\text {calc }} \\
(\mathrm{nm})\end{array}$ & $\begin{array}{l}E_{\text {calc }} \\
(\mathrm{eV})\end{array}$ & $f_{\text {os }}$ & major contributions (weight) ${ }^{d}$ \\
\hline \multirow[t]{8}{*}{$\mathbf{1}^{\prime}$} & 365 & 354 & 356 & 3.48 & 0.17 & $\begin{array}{l}\mathrm{H}-1 \rightarrow \mathrm{L}(54 \%) ; \mathrm{H}-1 \rightarrow \mathrm{L}+1(11 \%) ; \mathrm{H} \rightarrow \\
\mathrm{L}+1(24 \%)\end{array}$ \\
\hline & & & 354 & 3.50 & 0.15 & $\mathrm{H}-1 \rightarrow \mathrm{L}+1(75 \%) ; \mathrm{H} \rightarrow \mathrm{L}+1(14 \%)$ \\
\hline & & & 335 & 3.71 & 0.05 & $\mathrm{H}-2 \rightarrow \mathrm{L}(82 \%)$ \\
\hline & & & 290 & 4.27 & 0.05 & $\begin{array}{l}\mathrm{H}-1 \rightarrow \mathrm{L}+3(20 \%) ; \mathrm{H} \rightarrow \mathrm{L}+2(12 \%) \\
\mathrm{H} \rightarrow \mathrm{L}+5(21 \%) ; \mathrm{H} \rightarrow \mathrm{L}+7(13 \%)\end{array}$ \\
\hline & & & 278 & 4.46 & 0.03 & $\begin{array}{l}\mathrm{H}-1 \rightarrow \mathrm{L}+7(13 \%) ; \mathrm{H} \rightarrow \mathrm{L}+7(64 \%) ; \mathrm{H} \rightarrow \\
\mathrm{L}+8(15 \%)\end{array}$ \\
\hline & & & 278 & 4.47 & 0.03 & $\mathrm{H}-1 \rightarrow \mathrm{L}+7(74 \%) ; \mathrm{H}-1 \rightarrow \mathrm{L}+8(11 \%)$ \\
\hline & & & 234 & 5.30 & 0.03 & $\mathrm{H}-3 \rightarrow \mathrm{L}+1(93 \%)$ \\
\hline & & & 224 & 5.54 & 0.05 & $\mathrm{H}-7 \rightarrow \mathrm{L}(17 \%) ; \mathrm{H}-6 \rightarrow \mathrm{L}+1(55 \%)$ \\
\hline \multirow[t]{9}{*}{$\mathbf{2}^{\prime}$} & 423 & 424 & 436 & 2.84 & 0.20 & $\mathrm{H}-1 \rightarrow \mathrm{L}(93 \%)$ \\
\hline & & & 424 & 2.92 & 0.14 & $\mathrm{H}-2 \rightarrow \mathrm{L}+1(16 \%) ; \mathrm{H}-1 \rightarrow \mathrm{L}+1(72 \%)$ \\
\hline & & & 396 & 3.13 & 0.05 & $\mathrm{H}-2 \rightarrow \mathrm{L}(97 \%)$ \\
\hline & & & 393 & 3.16 & 0.12 & $\mathrm{H}-2 \rightarrow \mathrm{L}+1(81 \%) ; \mathrm{H}-1 \rightarrow \mathrm{L}+1(12 \%)$ \\
\hline & & & 323 & 3.83 & 0.03 & $\mathrm{H}-1 \rightarrow \mathrm{L}+2(45 \%) ; \mathrm{H} \rightarrow \mathrm{L}+8(34 \%)$ \\
\hline & & & 317 & 3.92 & 0.02 & $\begin{array}{l}\mathrm{H}-2 \rightarrow \mathrm{L}+2(10 \%) ; \mathrm{H}-2 \rightarrow \mathrm{L}+6(23 \%) \\
\mathrm{H} \rightarrow \mathrm{L}+3(42 \%) ; \mathrm{H} \rightarrow \mathrm{L}+8(12 \%)\end{array}$ \\
\hline & & & 291 & 4.26 & 0.08 & $\begin{array}{l}\mathrm{H}-2 \rightarrow \mathrm{L}+2(13 \%) ; \mathrm{H}-1 \rightarrow \mathrm{L}+2(23 \%) ; \mathrm{H} \\
\rightarrow \mathrm{L}+3(21 \%) ; \\
\mathrm{H} \rightarrow \mathrm{L}+5(17 \%)\end{array}$ \\
\hline & & & 274 & 4.53 & 0.04 & $\mathrm{H} \rightarrow \mathrm{L}+7(75 \%) ; \mathrm{H} \rightarrow \mathrm{L}+8(18 \%)$ \\
\hline & & & 253 & 4.89 & 0.06 & $\mathrm{H}-6 \rightarrow \mathrm{L}(85 \%)$ \\
\hline \multirow[t]{11}{*}{$3^{\prime}$} & 499 & 505 & 515 & 2.41 & 0.34 & $\mathrm{H}-1 \rightarrow \mathrm{L}(86 \%) ; \mathrm{H} \rightarrow \mathrm{L}+1(12 \%)$ \\
\hline & & & 487 & 2.55 & 0.16 & $\mathrm{H}-1 \rightarrow \mathrm{L}+1(82 \%)$ \\
\hline & & & 450 & 2.76 & 0.05 & $\mathrm{H}-2 \rightarrow \mathrm{L}(96 \%)$ \\
\hline & & & 444 & 2.79 & 0.06 & $\mathrm{H}-2 \rightarrow \mathrm{L}+1(89 \%)$ \\
\hline & & & 310 & 4.01 & 0.06 & $\begin{array}{l}\mathrm{H}-1 \rightarrow \mathrm{L}+4(12 \%) ; \mathrm{H} \rightarrow \mathrm{L}+5(25 \%) ; \mathrm{H} \rightarrow \\
\mathrm{L}+12(19 \%)\end{array}$ \\
\hline & & & 308 & 4.03 & 0.05 & $\mathrm{H}-1 \rightarrow \mathrm{L}+4(63 \%) ; \mathrm{H} \rightarrow \mathrm{L}+5(15 \%)$ \\
\hline & & & 298 & 4.16 & 0.03 & $\begin{array}{l}\mathrm{H}-1 \rightarrow \mathrm{L}+8(11 \%) ; \mathrm{H} \rightarrow \mathrm{L}+5(29 \%) ; \mathrm{H} \rightarrow \\
\mathrm{L}+12(23 \%)\end{array}$ \\
\hline & & & 297 & 4.18 & 0.05 & $\mathrm{H}-4 \rightarrow \mathrm{L}(77 \%) ; \mathrm{H}-1 \rightarrow \mathrm{L}+6(17 \%)$ \\
\hline & & & 290 & 4.28 & 0.07 & $\begin{array}{l}\mathrm{H}-5 \rightarrow \mathrm{L}(22 \%) ; \mathrm{H}-4 \rightarrow \mathrm{L}+1(21 \%) ; \mathrm{H}-1 \\
\rightarrow \mathrm{L}+9(23 \%)\end{array}$ \\
\hline & & & 260 & 4.77 & 0.30 & $\mathrm{H}-8 \rightarrow \mathrm{L}(64 \%)$ \\
\hline & & & 257 & 4.83 & 0.12 & $\mathrm{H}-8 \rightarrow \mathrm{L}+1(47 \%) ; \mathrm{H} \rightarrow \mathrm{L}+11(21 \%)$ \\
\hline \multirow[t]{6}{*}{$4^{\prime}$} & 525 & 525 & 536 & 2.32 & 0.39 & $\mathrm{H}-1 \rightarrow \mathrm{L}(89 \%)$ \\
\hline & & & 506 & 2.45 & 0.17 & $\mathrm{H}-1 \rightarrow \mathrm{L}+1(82 \%)$ \\
\hline & & & 464 & 2.67 & 0.06 & $\mathrm{H}-2 \rightarrow \mathrm{L}(97 \%)$ \\
\hline & & & 458 & 2.71 & 0.07 & $\mathrm{H}-2 \rightarrow \mathrm{L}+1(91 \%)$ \\
\hline & & & 314 & 3.95 & 0.25 & $\begin{array}{l}\mathrm{H}-5 \rightarrow \mathrm{L}+1(12 \%) ; \mathrm{H}-4 \rightarrow \mathrm{L}(14 \%) ; \mathrm{H} \rightarrow \\
\mathrm{L}+5(34 \%)\end{array}$ \\
\hline & & & 313 & 3.96 & 0.14 & $\mathrm{H}-1 \rightarrow \mathrm{L}+4(39 \%) ; \mathrm{H} \rightarrow \mathrm{L}+5(21 \%)$ \\
\hline
\end{tabular}

${ }^{a}$ All calculations used the LANL2DZ/6-311G/6-311G*/6-311+G* mixed basis set, with the B3LYP functional for $\mathbf{1}^{\prime}$ and $\mathbf{2}^{\prime}$, but PBE1PBE for $\mathbf{3}^{\prime}$ and $\mathbf{4}^{\prime}$. Only the main transitions within each band are included. ${ }^{b} \lambda_{\max }$ value for lowest energy band measured with 1-4 in MeCN. ${ }^{c}$ $\lambda_{\max }$ value derived from the simulated absorption spectrum. ${ }^{d} \mathrm{H}=\mathrm{HOMO}, \mathrm{L}=\mathrm{LUMO}$. 

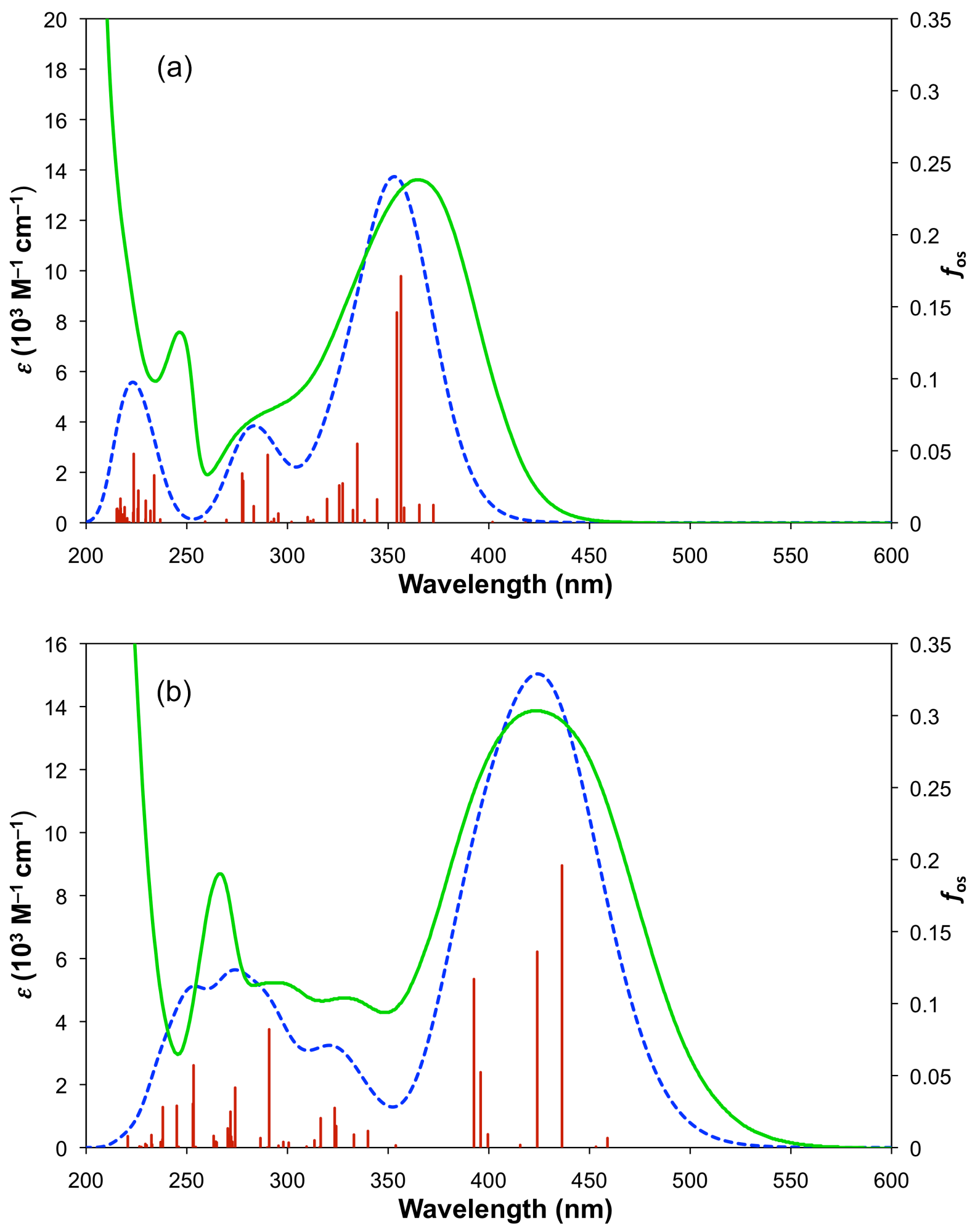

Figure 8. B3LYP/LANL2DZ/6-311G/6-311G*/6-311+G*-calculated (blue) UV-vis spectra of (a) $\mathbf{1}^{\prime}$ and (b) $\mathbf{2}^{\prime}$, and the corresponding experimental data (green). The $\varepsilon$-axes refer to the experimental data only and the vertical axes of the calculated data are scaled to match the main experimental absorptions. The oscillator strength axes refer to the individual calculated transitions (red). 


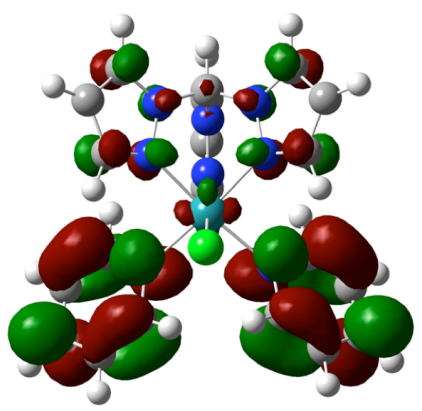

LUMO

(a)

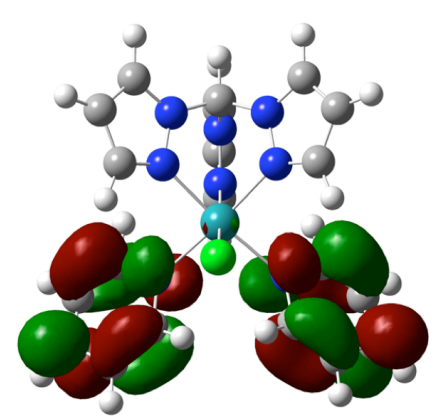

LUMO+1

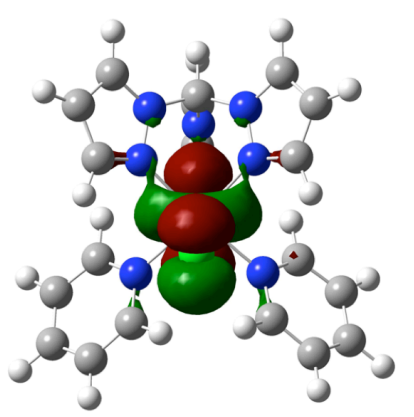

HOMO-2
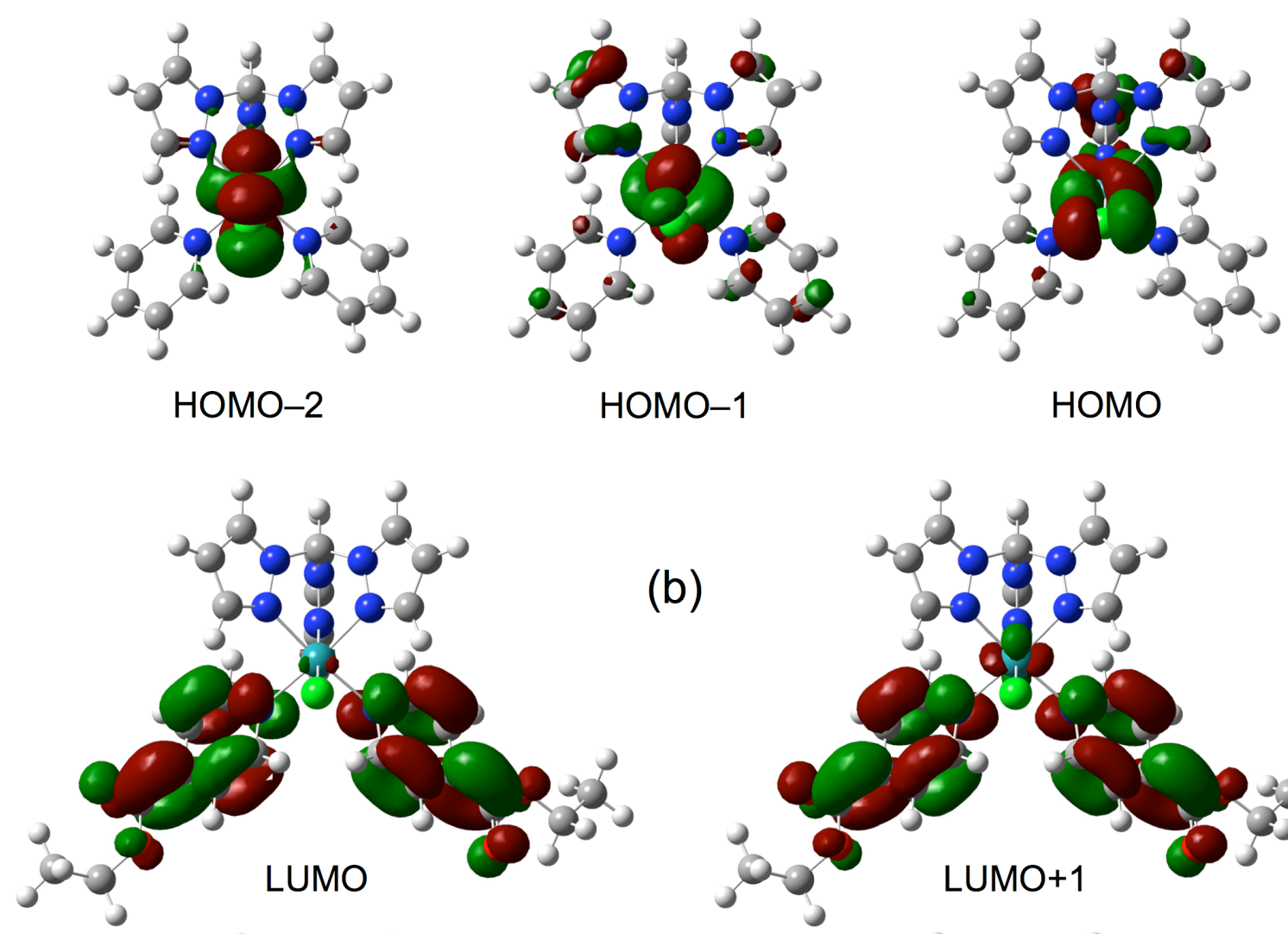

(b)
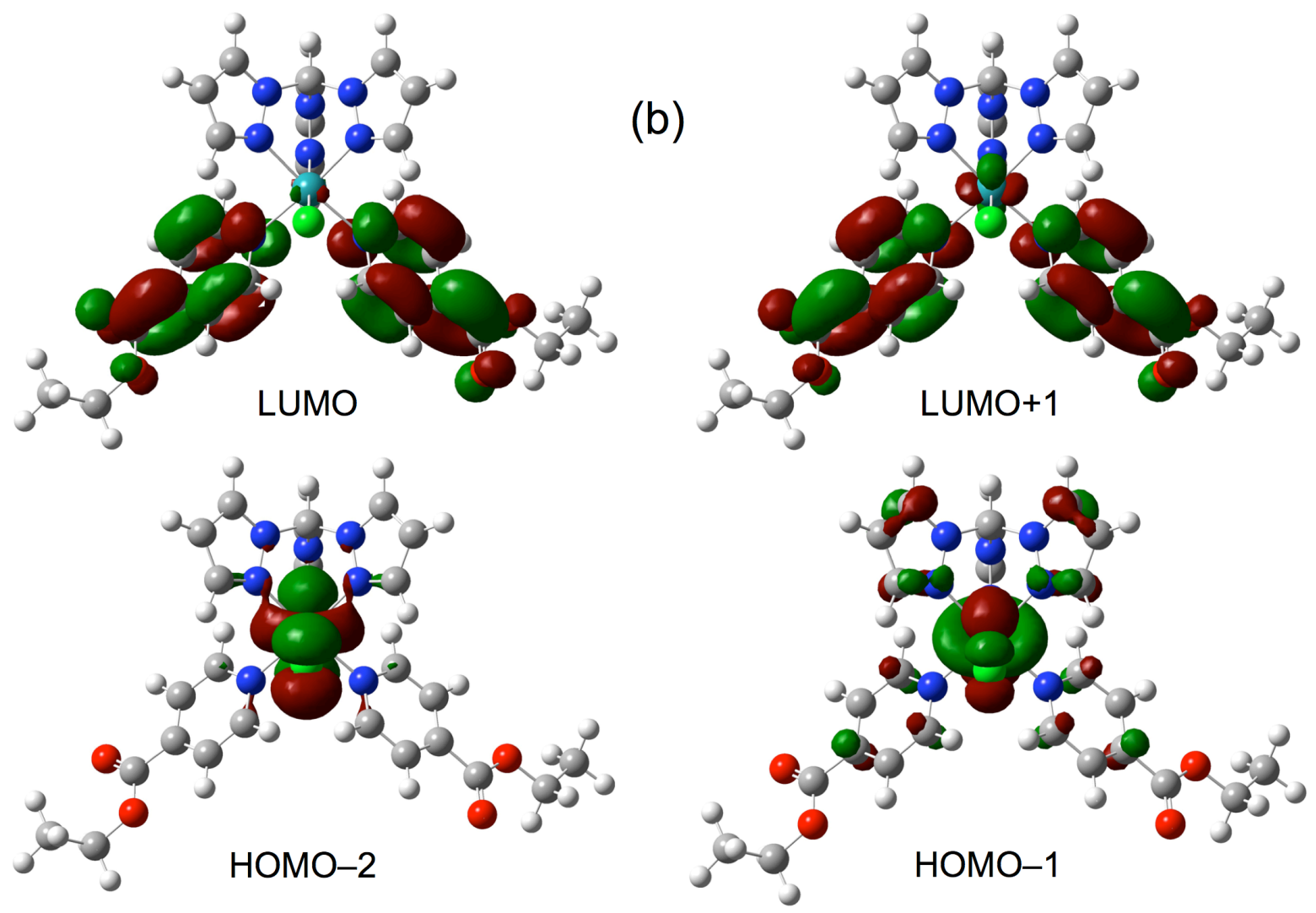

Figure 9. B3LYP/LANL2DZ/6-311G/6-311G*/6-311+G*-derived contour surface diagrams of the MOs involved in the dominant low energy electronic transitions for (a) $\mathbf{1}^{\prime}$ and (b) $\mathbf{2}^{\prime}$ (isosurface value $0.03 \mathrm{au}$ ). 
As observed experimentally, the higher energy region of the absorbance spectrum of $\mathbf{2}^{\prime}$ is relatively complex and is modeled about many, mostly weak transitions. Those in the region 275-350 $\mathrm{nm}$ can be assigned to MLCT directed towards both the EIN and Tpm ligands, while those below $275 \mathrm{~nm}$ have mainly EIN $\pi \rightarrow \pi^{*}$ character.

Table 7. TD-DFT-Calculated Orbital Energies for the Complexes $\mathbf{1}^{\prime}-\mathbf{4}^{\prime a}$

\begin{tabular}{lllll}
\hline orbital & $\mathbf{1}^{\prime}$ & $\mathbf{2}^{\prime}$ & $\mathbf{3}^{\prime}$ & $\mathbf{4}^{\prime}$ \\
\hline L+12 & & & -0.01 & -0.87 \\
L+11 & & & -0.41 & -0.97 \\
L+10 & & & -0.53 & -0.97 \\
L+9 & & & -1.03 & -1.04 \\
L+8 & -0.14 & -0.27 & -1.10 & -1.14 \\
L+7 & -0.52 & -0.58 & -1.16 & -1.17 \\
L+6 & -0.69 & -0.81 & -1.28 & -1.30 \\
L+5 & -0.82 & -0.99 & -1.39 & -1.52 \\
L+4 & -1.05 & -1.23 & -1.44 & -1.53 \\
L+3 & -1.16 & -1.25 & -1.84 & -1.90 \\
L+2 & -1.19 & -1.27 & -1.85 & -1.91 \\
L+1 & -1.57 & -2.43 & -3.22 & -3.35 \\
L & -1.62 & -2.46 & -3.28 & -3.40 \\
H & -5.76 & -5.89 & -6.28 & -6.28 \\
H-1 & -5.78 & -5.93 & -6.30 & -6.31 \\
H-2 & -6.17 & -6.31 & -6.71 & -6.72 \\
H-3 & -7.52 & -7.61 & -8.02 & -8.02 \\
H-4 & -7.58 & -7.62 & -8.04 & -8.02 \\
H-5 & -7.66 & -7.76 & -8.24 & -8.11 \\
H-6 & -7.74 & -7.89 & -8.35 & -8.13 \\
H-7 & -7.89 & -8.05 & -8.57 & -8.17 \\
H-8 & & & -8.60 & -8.17 \\
\hline
\end{tabular}

${ }^{a}$ All calculations used the LANL2DZ/6-311G/6-311G*/6-311+G* mixed basis set, with the B3LYP functional for $\mathbf{1}^{\prime}$ and $\mathbf{2}^{\prime}$, but PBE1PBE for $\mathbf{3}^{\prime}$ and $\mathbf{4}^{\prime}$. $\mathrm{H}=\mathrm{HOMO}, \mathrm{L}=\mathrm{LUMO}$.

Calculations on the complexes $\mathbf{3}^{\prime}$ and $\mathbf{4}^{\prime}$ with B3LYP do not model the LE band accurately, giving bathochromic shifts of ca. $40 \mathrm{~nm}$ when compared to the experimental data. Much better results are obtained by using instead the PBE1PBE functional, although this approach overestimates the LE band energies for $\mathbf{1}^{\prime}$ and $\mathbf{2}^{\prime}$. 

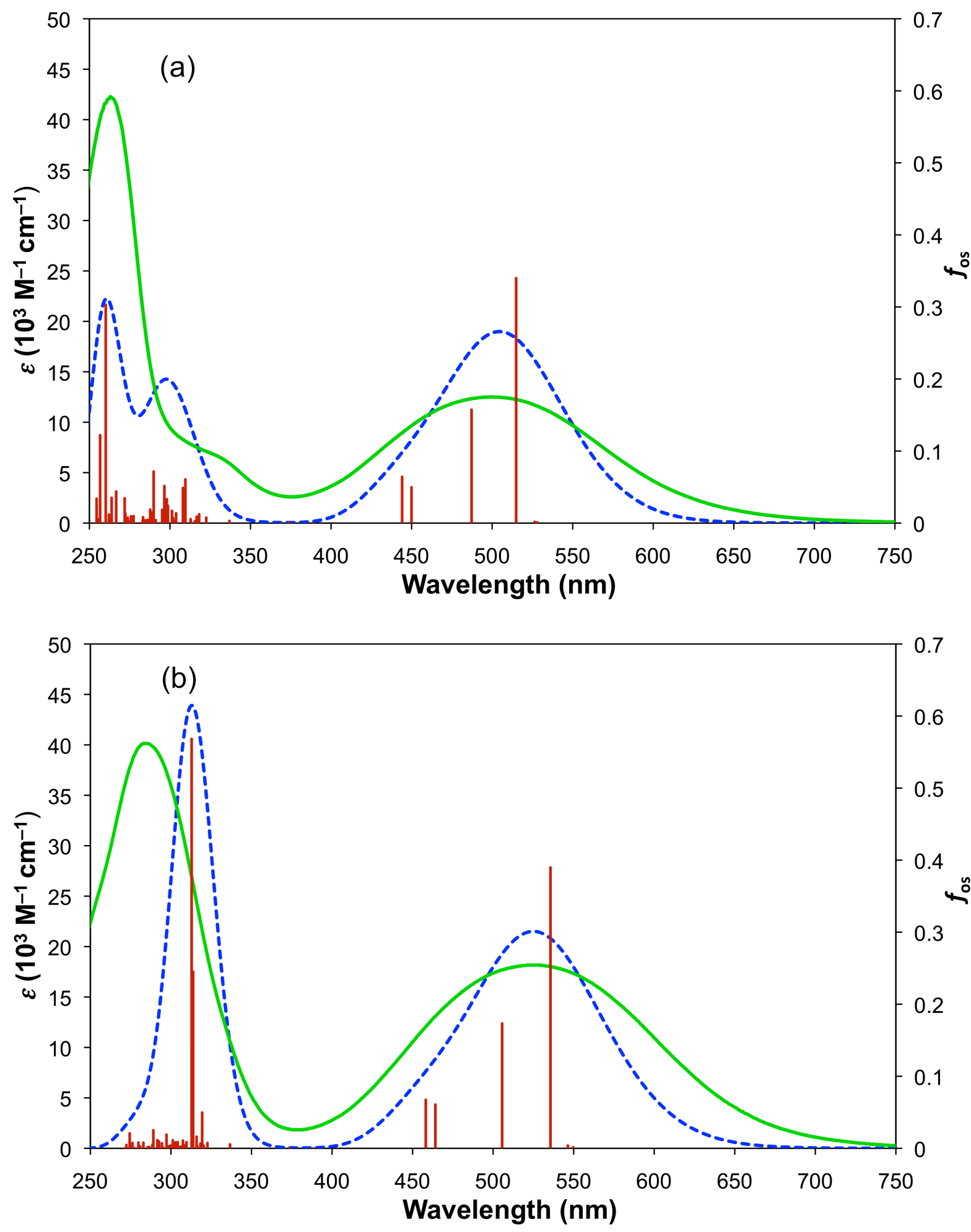

Figure 10. PBE1PBE/LANL2DZ/6-311G/6-311G*/6-311+G*-calculated (blue) UV-vis spectra of (a) $3^{\prime}$ and (b) $4^{\prime}$, and the corresponding experimental data (green). The $\varepsilon$-axes refer to the experimental data only and the vertical axes of the calculated data are scaled to match the main experimental absorptions. The oscillator strength axes refer to the individual calculated transitions (red). 


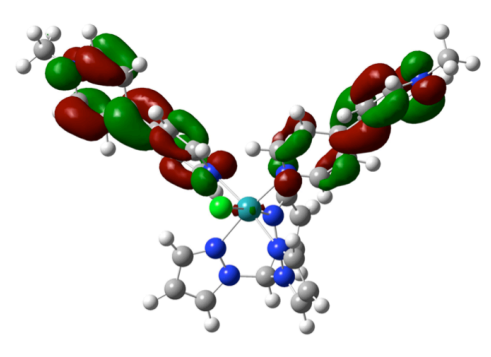

LUMO (a)

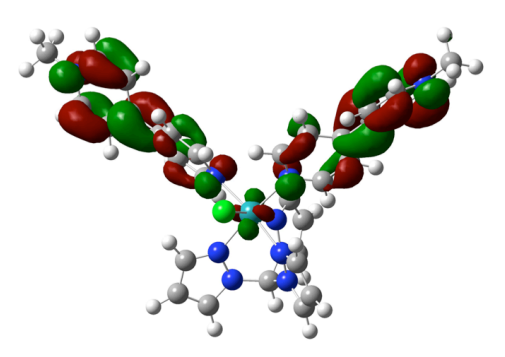

LUMO+1

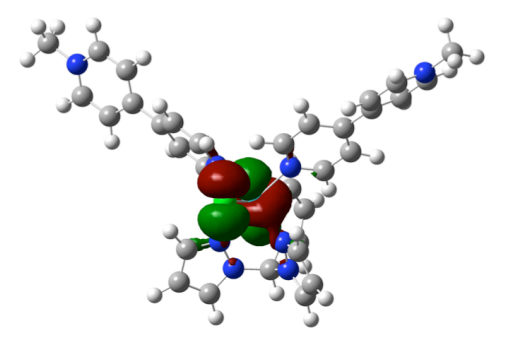

HOMO-2
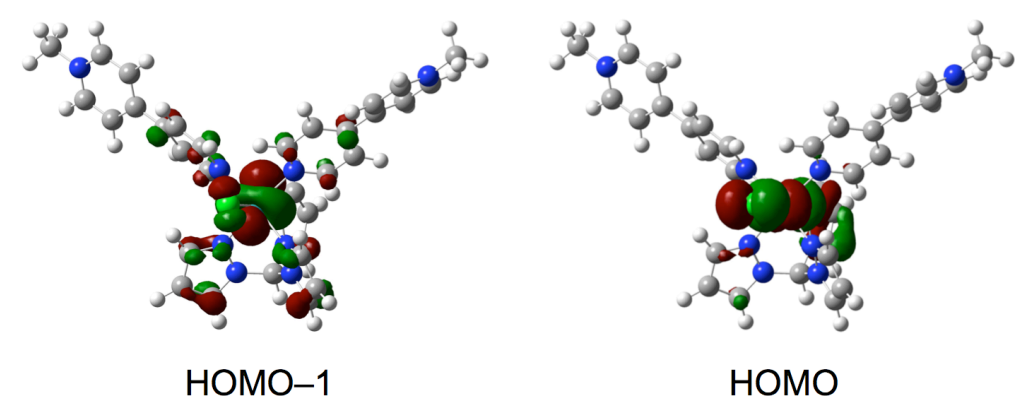

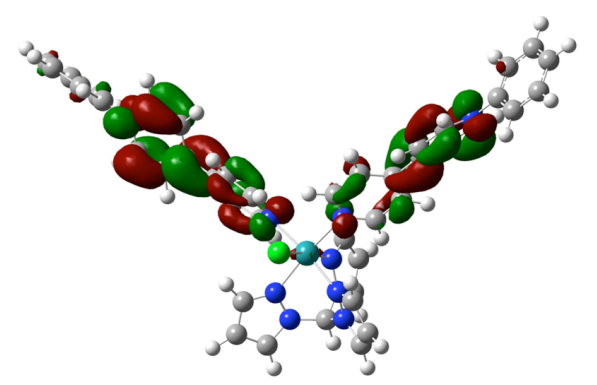

LUMO

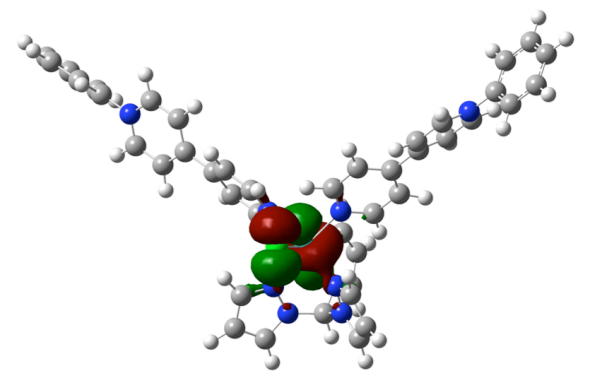

HOMO-2 (b)

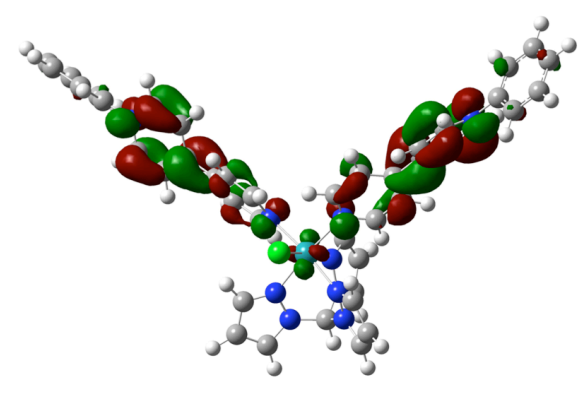

LUMO+1

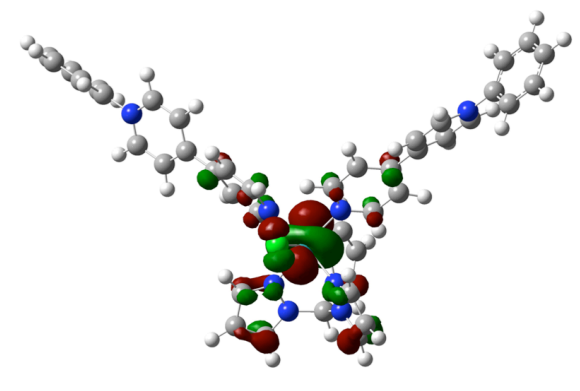

HOMO-1

Figure 11. PBE1PBE/LANL2DZ/6-311G/6-311G*/6-311+G*-derived contour surface diagrams of the MOs involved in the dominant low energy electronic transitions for (a) $\mathbf{3}^{\prime}$ and (b) $4^{\prime}$ (isosurface value $0.03 \mathrm{au}$ ). 
The spectra of $\mathbf{3}^{\prime}$ and $\mathbf{4}^{\prime}$ both exhibit very broad, LE bands that are modeled almost exclusively about four transitions of largely MLCT character. The orbitals involved in the main transitions contained within these bands are shown in Figures 11a and 11b, respectively, while the other orbitals mentioned in Table 6 are in the Supporting Information (Figures S3 and S4). The nature of the HOMO, HOMO-1 and HOMO-2 remains constant within the series $\mathbf{1}^{\prime}-\mathbf{4}^{\prime}$. For $\mathbf{3}^{\prime}$ and $\mathbf{4}^{\prime}$, the LUMO and LUMO+1 are $\pi^{*}$-orbitals of the $4,4^{\prime}$-bipyridyl units, weighted slightly in favor of the pyridinium rings. In a qualitative sense, the MO picture derived for these compounds resembles that reported previously for the related tetraammine complexes $\mathbf{5}^{\prime}$ and $\mathbf{6}^{\prime}$ (from gas-phase B3P86/LANL2DZ calculations that lack quantitative accuracy). ${ }^{9}$ On moving from $3^{\prime}$ to $4^{\prime}$, the LUMO and LUMO+1 are stabilised by 0.12-0.13 eV (Table 7) due to the mild electron-withdrawing influence of the Ph substituents. Because the energies of the donor orbitals are almost constant, the bathochromic shift in the absorption band is attributable primarily to the increased electron-accepting ability of the $\mathrm{PhQ}^{+}$ligands with respect to $\mathrm{MeQ}^{+}$. This conclusion is consistent with the electrochemical data (see above).

The highest energy band in $\mathbf{3}^{\prime}$ comprises numerous transitions of mixed LLCT/ILCT character, directed towards the pyridinium moieties. These transitions originate from a combination of $\pi$-orbitals located on Tpm and the pyridyl rings of the $\mathrm{MeQ}^{+}$ligands, as well as a contribution from the $\mathrm{Cl}^{-}$ligand. The intermediate energy band at ca. $300 \mathrm{~nm}$ includes transtions of MLCT character dircted towards the Tpm ligand. The intense band at ca. 285 $\mathrm{nm}$ in $\mathbf{4}^{\prime}$ is primarily based on two intense transitions of mixed LLCT/ILCT character, involving $\mathrm{PhQ}^{+} \pi^{*}$-orbitals that include a minor contribution from the $\mathrm{Ph}$ substituent.

The results of $\beta_{0}$ calculations on $\mathbf{2}^{\prime} \mathbf{- \mathbf { 4 } ^ { \prime }}$ are shown in Table 8. Using either B3LYP or PBE1PBE for $\mathbf{2}^{\prime}$ gives broadly similar results, with $\beta_{\mathrm{tot}} \approx 100 \times 10^{-30} \mathrm{esu}$ in MeCN. Calculations conducted in the gas phase afford consistently smaller values for $\beta_{\text {tot }}$ and all individual $\beta$ components when compared with $\mathrm{MeCN}$ solution. A similarly large solvation effect has been observed with mono- and bimetallic $\mathrm{Ru}^{\mathrm{II}}$ ammine complexes treated at the B3LYP level of theory. ${ }^{44}$ Given the axis convention adopted in the calculations (Figure 1; see 
also the Supporting Information, Figure S5), $\beta_{y}$ dominates and $\beta_{x x y}$ is the most significant of the "off-diagonal" tensor components.

For $\mathbf{3}^{\prime}$ and $\mathbf{4}^{\prime}$, again including the solvent increases $\beta_{\text {tot }}$ with respect to the gas phase, but the difference is relatively small for $\mathbf{3}^{\prime}$. Interestingly, $\beta_{\text {tot }}$ increases substantially on moving from $3^{\prime}$ to $4^{\prime}$ in $\mathrm{MeCN}$, but a corresponding slight decrease is predicted in the gas phase. Clearly, the data calculated in solution are expected to best model the measured parameters, and when using PBE1PBE in each case, $\beta_{\text {tot }}\left(10^{-30}\right.$ esu $)$ increases from ca. 100 for $\mathbf{2}^{\prime}$ to ca. 300 for $\mathbf{3}^{\prime}$, then ca. 440 for $\mathbf{4}^{\prime}$. These predictions agree relatively well with the $\beta_{0}$ values determined via Stark spectroscopy (Table 5), indicating that the HRS measurements give a less reliable indication of the NLO responses for these complexes. It is also worth noting that previous finite-field calculations on $\mathbf{5}^{\prime}$ and $\mathbf{6}^{\prime}$ predict that the total $\beta_{0}$ value increases (by ca. 30\%) when the Me substituents are replaced with $\mathrm{Ph} .{ }^{9 b}$ When compared with $\mathbf{2}^{\prime}$, the $\pi$-conjugated molecular frameworks of $\mathbf{3}^{\prime}$ and $4^{\prime}$ are extended along the $y$ direction, so the relative dominance of the $\beta_{y}$ and $\beta_{x x y}$ terms increases. 
Table 8. First Hyperpolarizabilities $\left(10^{-30} \mathrm{esu}\right)$ Calculated via DFT for the Complexes $\mathbf{1}^{\prime}-\mathbf{4}^{\prime a}$

\begin{tabular}{|c|c|c|c|c|c|c|c|c|c|c|c|c|c|c|c|}
\hline complex & functional & $\beta_{x x x}$ & $\beta_{x x y}$ & $\beta_{x y y}$ & $\beta_{y y y}$ & $\beta_{x x z}$ & $\beta_{x y z}$ & $\beta_{y y z}$ & $\beta_{x z z}$ & $\beta_{y z z}$ & $\beta_{z z z}$ & $\beta_{x}$ & $\beta_{y}$ & $\beta_{z}$ & $\beta_{\mathrm{tot}}$ \\
\hline $2^{\prime b}$ & B3LYP & -16.9 & 66.8 & 8.95 & 39.3 & 6.60 & -8.79 & 3.38 & 0.38 & -3.62 & 13.1 & -7.57 & 102 & 23.1 & 105 \\
\hline $\mathbf{2}^{\prime c}$ & B3LYP & -5.81 & 23.7 & 3.27 & 11.4 & 2.06 & -2.94 & 1.28 & 0.62 & -2.44 & 6.88 & -1.92 & 32.7 & 10.2 & 34.3 \\
\hline $\mathbf{2}^{\prime b}$ & PBE1PBE & -14.6 & 59.8 & 7.92 & 34.3 & 5.33 & -7.69 & 2.66 & 0.40 & -3.37 & 11.7 & -6.23 & 90.7 & 19.7 & 93.0 \\
\hline $\mathbf{2}^{\prime c}$ & PBE1PBE & -5.07 & 21.3 & 2.85 & 9.99 & 1.65 & -2.58 & 0.99 & 0.54 & -2.13 & 6.10 & -1.68 & 29.1 & 8.73 & 30.5 \\
\hline $\mathbf{3}^{\prime b}$ & PBE1PBE & -0.48 & 217 & 1.59 & 82.1 & 21.3 & -0.07 & 8.75 & 0.98 & -4.35 & 10.4 & 2.10 & 295 & 40.4 & 298 \\
\hline $\mathbf{3}^{\prime c}$ & PBE1PBE & 2.10 & 211 & 2.68 & 68.1 & 19.8 & 0.19 & 7.15 & 0.47 & -1.62 & 4.57 & 5.25 & 277 & 31.5 & 279 \\
\hline $4^{\prime b}$ & PBE1PBE & 6.66 & 254 & 1.42 & 96.3 & 18.2 & -0.38 & 7.80 & 1.55 & -4.64 & 10.6 & 9.64 & 346 & 36.7 & 348 \\
\hline $4^{\prime c}$ & PBE1PBE & 9.44 & 197 & 2.25 & 59.7 & 13.8 & -0.31 & 5.08 & 0.68 & -1.99 & 4.75 & 12.4 & 255 & 23.7 & 256 \\
\hline
\end{tabular}

${ }^{a}$ All calculations used the LANL2DZ/6-311G/6-311G*/6-311+G* mixed basis set. ${ }^{b}$ In MeCN. ${ }^{c}$ In the gas phase. 


\section{Conclusion}

We have synthesized and characterized several new $\mathrm{Ru}$ (II $(\mathrm{Tpm})$ complexes. Their UV-vis absorption spectra are dominated by intense, single-maximum MLCT bands, the energies of which correlate with the electron-accepting ability of the pyridine/pyridyl $\left(\mathrm{L}^{\mathrm{A}}\right)$ ligands. The $\mathrm{Ru}^{\mathrm{III} / \mathrm{II}}$ oxidation waves measured by cyclic voltammetry in $\mathrm{MeCN}$ are reversible, with $E_{1 / 2}$ covering a range of $0.80-0.93 \mathrm{~V}$ vs $\mathrm{Ag}-\mathrm{AgCl}$, while the ligand-based reduction potentials show larger variations. Single crystal X-ray structures have been determined for three complex salts, revealing centrosymmetric packing structures. The values of $\beta_{800}$ measured via the HRS technique in $\mathrm{MeCN}$ are relatively large, but show little dependence on $\mathrm{L}^{\mathrm{A}}$. In contrast, the $\beta_{0}$ values estimated from Stark spectroscopic data measured for the lowest energy absorption bands in PrCN at $77 \mathrm{~K}$ increase substantially with the electron-accepting strength of $\mathrm{L}^{\mathrm{A}}$. TD-DFT calculations confirm that the latter bands have largely $\mathrm{Ru}^{\mathrm{II}} \rightarrow \mathrm{L}^{\mathrm{A}}$ MLCT character, while $\mathrm{Ru}^{\mathrm{II}} \rightarrow$ Tpm MLCT transitions occur at higher energies. $\beta_{0}$ values predicted via DFT concur with the Stark measurements, showing large increases as $\mathrm{L}^{\mathrm{A}}$ becomes more electron deficient. Comparisons with the experimental data reported previously for related complexes do not show clearly whether a $c i s-\left\{\mathrm{Ru}^{\mathrm{II}}\left(\mathrm{NH}_{3}\right)_{4}\right\}^{2+}$ or $\left\{\mathrm{Ru}^{\mathrm{II}} \mathrm{Cl}(\mathrm{Tpm})\right\}^{+}$center gives larger NLO responses. However, the greater electron-richness at the metal imparted by having ammine ligands is apparent from the MLCT absorption and electrochemical data.

Acknowledgement. We thank the EPSRC for support (grant EP/G02099) and also the Fund for Scientific Research-Flanders (FWO-V, G.0312.08) and the University of Leuven (GOA/2011/03). B.S.B. acknowledges the Beckman Institute of the California Institute of Technology for support. We are grateful to James Amphlett (Manchester) for assistance with the purification of complex salt 3, and to Nick Van Steerteghem (Leuven) for help with the HRS experiments.

Supporting Information Available: Crystallographic information in CIF format; 
Cartesian coordinates of theoretically-optimized geometries for the complexes $\mathbf{1}^{\prime}-\mathbf{4}^{\prime}$; additional MO figures and depictions of axis convention used in the calculations; This material is available free of charge via the Internet at http://pubs.acs.org.

\section{References}

(1) (a) Bennett, M. A.; Bruce, M. I.; Cifuentes, M. P.; Deeming, A. J.; Haines, R. J.; Hill, A. F.; Humphrey, M. G.; Khan, K.; Pomeroy, R. K.; Sappa, E.; Smith, A. K.; Wenger, E. In Comprehensive Organometallic Chemistry II; Abel, E. W.; Stone, F. G. A.; Wilkinson, G., Eds.; Pergamon Press: Oxford, U.K., 1995; Vol. 7, pp 291-960. (b) Che, C.-M.; Housecroft, C. E.; Lau, T.-C. In Comprehensive Coordination Chemistry II; McCleverty, J. A.; Meyer, T. J., Eds.; Pergamon Press: Oxford, U.K., 2004; Vol. 5, pp 555-847. (c) Butler, I. R.; Cadierno, V.; Cifuentes, M. P.; Crochet, P.; Dyson, P. J.; Gimeno, J.; Humphrey, M. G.; Johnson, A. L.; Leong, B. K. L.; McIndoe, J. S.; Pomeroy, R. K.; Raithby, P. R.; Sappa, E.; Suzuki, H.; Takao, T.; Thomas, D.; Whittlesey, M. K.; Wilton-Ely, J. D.; Wong, W.-T. In Comprehensive Organometallic Chemistry III; Crabtree, R. H.; Mingos, D. M. P., Eds.; Pergamon Press: Oxford, U.K., 2007; Vol. 6, pp 353-1116.

(2) Selected recent reviews: (a) Samojłowicz, C.; Bieniek, M.; Grela, K. Chem. Rev. 2009, 109, 3708. (b) Concepcion, J. J.; Jurss, J. W.; Brennaman, M. K.; Hoertz, P. G.; Patrocinio, A. O. T.; Murakami Iha, N. Y.; Templeton, J. L.; Meyer, T. J. Acc. Chem. Res. 2009, 42, 1954. (c) Nolan, S. P.; Clavier, H. Chem. Soc. Rev. 2010, 39, 3305. (d) Muratsugu, S.; Tada, M. Acc. Chem. Res. 2013, 46, 300. (e) Kozhushkov, S. I.; Ackermann, L. Chem. Sci. 2013, 4, 886 .

(3) Selected recent reviews: (a) Ang, W. H.; Dyson, P. J. Eur. J. Inorg. Chem. 2006, 4003. (b) Bruijnincx, P. C. A.; Sadler, P. J. Adv. Inorg. Chem. 2009, 61, 1. (c) Süss-Fink, G. Dalton Trans. 2010, 39, 1673. (d) Smith, G. S.; Therrien, B. Dalton Trans. 2011, 40, 10793. (e) Noffke, A. L.; Habtemariam, A.; Pizarro, A. M.; Sadler, P. J. Chem. Commun. 2012, 48, 5219. 
(4) Selected recent reviews: (a) Balzani, V.; Juris, A. Coord. Chem. Rev. 2001, 211, 97. (b) Vos, J. G.; Kelly, J. M. Dalton Trans. 2006, 4869. (c) Campagna, S.; Puntoriero, F.; Nastasi, F.; Bergamini, G.; Balzani, V. Top. Curr. Chem. 2007, 280, 117. (d) Herman, L.; Ghosh, S.; Defrancq, E.; Kirsch-De Mesmaeker, A. J. Phys. Org. Chem. 2008, 21, 670. (e) Bonnet, S.; Collin, J.-P. Chem. Soc. Rev. 2008, 37, 1207.

(5) Selected examples: (a) Buda, M.; Kalyuzhny, G.; Bard, A. J. J. Am. Chem. Soc. 2002, 124, 6090. (b) Welter, S.; Brunner, K.; Hofstraat, J. W.; De Cola, L. Nature 2003, 421, 54. (c) Tung, Y.-L.; Chen, L.-S.; Chi, Y.; Chou, P.-T.; Cheng, Y.-M.; Li, E. Y.; Lee, G.-H.; Shu, C.-F.; Wu, F.-I.; Carty, A. J. Adv. Funct. Mater. 2006, 16, 1615. (d) Chou, P.-T.; Chi, Y. Chem. Eur. J. 2007, 13, 380. (e) Zhu, Y.-Y.; Gu, C.; Tang, S.; Fei, T.; Gu, X.; Wang, H.; Wang, Z.-M.; Wang, F.-F.; Lu, D.; Ma, Y.-G. J. Mater. Chem. 2009, 19, 3941.

(6) Selected recent reviews: (a) Ardo, S.; Meyer, G. J. Chem. Soc. Rev. 2009, 38, 115. (b) Hagfeldt, A.; Boschloo, G.; Sun, L.-C.; Kloo, L.; Pettersson, H. Chem. Rev. 2010, 110, 6595. (c) Clifford, J. N.; Martínez-Ferrero, E.; Viterisi, A.; Palomares, E. Chem. Soc. Rev. 2011, 40, 1635. (d) Reynal, A.; Palomares, E. Eur. J. Inorg. Chem. 2011, 4509. (e) Robson, K. C. D.; Bomben, P. G.; Berlinguette, C. P. Dalton Trans. 2012, 41, 7814.

(7) Recent reviews on NLO-active metal complexes, with a substantial coverage of $\mathrm{Ru}$ : (a) Coe, B. J. In Comprehensive Coordination Chemistry II; McCleverty, J. A.; Meyer, T. J., Eds.; Elsevier Pergamon: Oxford, U.K., 2004; Vol. 9, pp 621-687. (b) Maury, O.; Le Bozec, H. Acc. Chem. Res. 2005, 38, 691. (c) Coe, B. J. Acc. Chem. Res. 2006, 39, 383. (d) Coe, B. J. In Nonlinear Optical Properties of Matter: From Molecules to Condensed Phases; Papadopoulos, M. G.; Leszczynski, J.; Sadlej, A. J., Eds.; Springer: Dordrecht, 2006, pp 571608. (e) Morrall, J. P.; Dalton, G. T.; Humphrey, M. G.; Samoc, M. Adv. Organomet. Chem. 2007, 55, 61. (f) Di Bella, S.; Dragonetti, C.; Pizzotti, M.; Roberto, D.; Tessore, F.; Ugo, R. Top. Organomet. Chem. 2010, 28, 1. (g) Maury, O.; Le Bozec, H. In Molecular Materials; Bruce, D. W.; O’Hare, D.; Walton, R. I., Eds.; Wiley: Chichester, U.K., 2010; pp 1-59. (h) Coe, B. J. Coord. Chem. Rev. 2013, 257, 1438.

(8) (a) Nonlinear Optics of Organic Molecules and Polymers; Nalwa, H. S., Miyata, S., Eds.; CRC Press: Boca Raton, FL, 1997. (b) Nonlinear Optical Properties of Matter: 
From Molecules to Condensed Phases; Papadopoulos, M. G.; Leszczynski, J.; Sadlej, A. J., Eds.; Springer: Dordrecht, 2006. (c) De Meulenaere, E.; Chen, W.-Q.; Van Cleuvenbergen, S.; Zheng, M.-L.; Psilodimitrakopoulos, S.; Paesen, R.; Taymans, J.-M.; Ameloot, M.; Vanderleyden, J.; Loza-Alvarez, P.; Duan, X.-M.; Clays, K. Chem. Sci. 2012, 3, 984 and references therein.

(9) (a) Coe, B. J.; Harris, J. A.; Jones, L. A.; Brunschwig, B. S.; Song, K.; Clays, K.; Garín, J.; Orduna, J.; Coles, S. J.; Hursthouse, M. B. J. Am. Chem. Soc. 2005, 127, 4845. (b) Coe, B. J.; Foxon, S. P.; Harper, E. C.; Helliwell, M.; Raftery, J.; Swanson, C. A.; Brunschwig, B. S.; Clays, K.; Franz, E.; Garín, J.; Orduna, J.; Horton, P. N.; Hursthouse, M. B. J. Am. Chem. Soc. 2010, 132, 1706.

(10) Selected examples: (a) Barqawi, K. R.; Llobet, A.; Meyer, T. J. J. Am. Chem. Soc. 1988, 110, 7751. (b) Llobet, A.; Curry, M. E.; Evans, H. T.; Meyer, T. J. Inorg. Chem. 1989, 28, 3131. (c) Jones, W. E. Jr.; Bignozzi, C. A.; Chen, P.-Y.; Meyer, T. J. Inorg. Chem. 1993, 32, 1167. (d) Field, L. D.; Messerle, B. A.; Soler, L.; Buys, I. E.; Hambley, T. W. J. Chem. Soc., Dalton Trans. 2001, 1959. (e) Wilson, D. C.; Nelson, J. H. J. Organomet. Chem. 2003, 682, 272. (f) Katz, N. E.; Romero, I.; Llobet, A.; Parella, T.; Benet-Buchholz, J. Eur. J. Inorg. Chem. 2005, 272. (g) Iengo, E.; Zangrando, E.; Baiutti, E.; Munini, F.; Alessio, E. Eur. J. Inorg. Chem. 2005, 1019. (h) Katz, N. E.; Fagalde, F.; Lis de Katz, N. D.; Mellace, M. G.; Romero, I.; Llobet, A.; Benet-Buchholz, J. Eur. J. Inorg. Chem. 2005, 3019. (i) Foxon, S. P.; Metcalfe, C.; Adams, H.; Webb, M.; Thomas, J. A. Inorg. Chem. 2007, 46, 409. (j) Kuzu, I.; Nied, D.; Breher, F. Eur. J. Inorg. Chem. 2009, 872. (k) Waywell, P.; Gonzalez, V.; Gill, M. R.; Adams, H.; Meijer, A. J. H. M.; Williamson, M. P.; Thomas, J. A. Chem. Eur. J. 2010, 16, 2407. (1) De, P.; Mondal, T. K.; Mobin, S. M.; Lahiri, G. K. Inorg. Chim. Acta 2011, 372, 250. (m) Agarwala, H.; Das, D.; Mobin, S. M.; Mondal, T. K.; Lahiri, G. K. Inorg. Chim. Acta 2011, 374, 216. (n) Serrano, I.; López, M. I.; Ferrer, I.; Poater, A.; Parella, T.; Fontrodona, X.; Solà, M.; Llobet, A.; Rodríguez, M.; Romero, I. Inorg. Chem. 2011, 50, 6044. (o) Zagermann, J.; Klein, K.; Merz, K.; Molon, M; Metzler-Nolte, N. Eur. J. Inorg. Chem. 2011, 4212. (p) Cadranel, A.; Alborés, P.; Yamazaki, S.; Kleiman, V. D.; Baraldo, L. M. Dalton Trans. 2012, 41, 5343. (q) Agarwala, H.; Ehret, F.; Chowdhury, A. D.; Maji, S.; 
Mobin, S. M.; Kaim, W.; Lahiri, G. K. Dalton Trans. 2013, 42, 3721. (r) Guelfi, M.; Puntoriero, F.; Arrigo, A.; Serroni, S.; Cifelli, M.; Denti, G. Inorg. Chim. Acta 2013, 398, 19. (s) Coe, B. J.; Raftery, J.; Rusanova, D. Acta Crystallogr., Sect E, 2013, 69, m549.

(11) Reger, D. L.; Grattan, T. C.; Brown, K. J.; Little, C. A.; Lamba, J. J. S.; Rheingold, A. L.; Sommer, R. D. J. Organomet. Chem. 2000, 607, 120.

(12) Llobet, A.; Doppelt, P.; Meyer, T. J. Inorg. Chem. 1988, 27, 514.

(13) Xu, H.-J.; Cheng, Y.; Sun, J.-F.; Dougan, B. A.; Li, Y.-Z.; Chen, X.-T.; Xue, Z.L. J. Organomet. Chem. 2008, 693, 3851.

(14) Yonemoto, E. H.; Riley, R. L.; Kim, Y. I.; Atherton, S. J.; Schmehl, R. H.; Mallouk, T. E. J. Am. Chem. Soc. 1992, 114, 8081.

(15) Coe, B. J.; Harris, J. A.; Harrington, L. J.; Jeffery, J. C.; Rees, L. H.; Houbrechts S.; Persoons, A. Inorg. Chem. 1998, 37, 3391.

(16) SAINT (Version 6.45) and SADABS (Version 2.10), Bruker AXS Inc.; Madison: Wisconsin, USA, 2003.

(17) Sheldrick, G. M. Acta Crystallogr., Sect. A 1990, 46, 467.

(18) Sheldrick, G. M. SHELXL 97, Program for crystal structure refinement; University of Göttingen: Göttingen, Germany, 1997.

(19) SHELXTL (Version 6.10), Bruker AXS Inc.; Madison: Wisconsin, USA, 2000.

(20) (a) Olbrechts, G.; Strobbe, R.; Clays, K.; Persoons, A. Rev. Sci. Instrum. 1998, 69, 2233. (b) Olbrechts, G.; Wostyn, K.; Clays, K.; Persoons, A. Optics Lett. 1999, 24, 403. (c) Clays, K.; Wostyn, K.; Olbrechts, G.; Persoons, A.; Watanabe, A.; Nogi, K.; Duan, X.M.; Okada, S.; Oikawa, H.; Nakanishi, H.; Vogel, H.; Beljonne, D.; Brédas, J.-L. J. Opt. Soc. Am. B 2000, 17, 256.

(21) Heesink, G. J. T.; Ruiter, A. G. T.; van Hulst, N. F.; Bölger, B. Phys. Rev. Lett. 1993, 71, 999.

(22) (a) Shin, Y. K.; Brunschwig, B. S.; Creutz, C.; Sutin, N. J. Phys. Chem. 1996, 100, 8157. (b) Coe, B. J.; Harris, J. A.; Brunschwig, B. S. J. Phys. Chem. A 2002, 106, 897. 
(23) (a) Liptay, W. In Excited States, Vol. 1; Lim, E. C., Ed.; Academic Press, New York, 1974, pp. 129-229. (b) Bublitz, G. U.; Boxer, S. G. Annu. Rev. Phys. Chem. 1997, 48, 213. (c) Brunschwig, B. S.; Creutz, C.; Sutin, N. Coord. Chem. Rev. 1998, 177, 61.

(24) Gaussian 09, Revision A.02, Frisch, M. J.; Trucks, G. W.; Schlegel, H. B.; Scuseria, G. E.; Robb, M. A.; Cheeseman, J. R.; Scalmani, G.; Barone, V.; Mennucci, B.; Petersson, G. A.; Nakatsuji, H.; Caricato, M.; Li, X.; Hratchian, H. P.; Izmaylov, A. F.; Bloino, J.; Zheng, G.; Sonnenberg, J. L.; Hada, M.; Ehara, M.; Toyota, K.; Fukuda, R.; Hasegawa, J.; Ishida, M.; Nakajima, T.; Honda, Y.; Kitao, O.; Nakai, H.; Vreven, T.; Montgomery, Jr., J. A.; Peralta, J. E.; Ogliaro, F.; Bearpark, M.; Heyd, J. J.; Brothers, E.; Kudin, K. N.; Staroverov, V. N.; Kobayashi, R.; Normand, J.; Raghavachari, K.; Rendell, A.; Burant, J. C.; Iyengar, S. S.; Tomasi, J.; Cossi, M.; Rega, N.; Millam, N. J.; Klene, M.; Knox, J. E.; Cross, J. B.; Bakken, V.; Adamo, C.; Jaramillo, J.; Gomperts, R.; Stratmann, R. E.; Yazyev, O.; Austin, A. J.; Cammi, R.; Pomelli, C.; Ochterski, J. W.; Martin, R. L.; Morokuma, K.; Zakrzewski, V. G.; Voth, G. A.; Salvador, P.; Dannenberg, J. J.; Dapprich, S.; Daniels, A. D.; Farkas, Ö.; Foresman, J. B.; Ortiz, J. V.; Cioslowski, J.; Fox, D. J. Gaussian, Inc., Wallingford CT, 2009.

(25) (a) Perdew, J. P. Phys. Rev. B 1986, 33, 8822. (b) Becke, A. D. Phys. Rev. A, 1988, 38,3098 .

(26) Becke, A. D. J. Chem. Phys. 1993, 98, 5648.

(27) Yanai, T.; Tew, D. P.; Handy, N. C. Chem. Phys. Lett. 2004, 393, 51.

(28) Adamo C.; Barone, V. J. Chem. Phys. 1999, 110, 6158.

(29) Zhao Y.; Truhlar, D. Theor. Chem. Acc. 2008, 120, 215.

(30) (a) Hay, P. J.; Wadt, W. R. J. Chem. Phys. 1985, 82, 270. (b) Hay, P. J.; Wadt, W. R. J. Chem. Phys. 1985, 82, 299.

(31) (a) Barone, V.; Cossi, M. J. Phys. Chem. A 1998, 102, 1995. (b) Cossi, M.; Rega, N.; Scalmani, G.; Barone, V. J. Comput. Chem. 2003, 24, 669.

(32) O’Boyle, N. M.; Tenderholt, A. L.; Langner, K. M. J. Comput. Chem. 2008, 29, 839. 
(33) Thanthiriwatte, K. S.; Nalin de Silva, K. M. J. Mol. Struct. (Theochem) 2002, $617,169$.

(34) Selected examples: (a) Adeyemi, S. A.; Miller, F. J.; Meyer, T. J. Inorg. Chem. 1972, 11, 994. (b) Adeyemi, S. A.; Johnson, E. C.; Miller, F. J.; Meyer, T. J. Inorg. Chem. 1973, 12, 2371. (c) Coe, B. J.; Meyer, T. J.; White, P. S. Inorg. Chem. 1995, 34, 593. (d) Coe, B. J.; Chery, M.; Beddoes, R. L.; Hope, H.; White, P. S. J. Chem. Soc., Dalton Trans. 1996, 3917. (e) Coe, B. J.; Beyer, T.; Jeffery, J. C.; Coles, S. J.; Gelbrich, T.; Hursthouse, M. B.; Light, M. E. J. Chem. Soc., Dalton Trans. 2000, 797.

(35) (a) Coe, B. J. Chem. Eur. J. 1999, 5, 2464. (b) Asselberghs, I.; Clays, K. ; Persoons, A.; Ward, M. D. ; McCleverty, J. A. J. Mater. Chem. 2004, 14, 2831.

(36) Coe, B. J.; Harris, J. A.; Harrington, L. J.; Jeffery, J. C.; Rees, L. H.; Houbrechts S.; Persoons, A. Inorg. Chem. 1998, 37, 3391.

(37) Coe, B. J.; Jones, L. A.; Harris, J. A.; Sanderson, E. E.; Brunschwig, B. S.; Asselberghs, I.; Clays, K.; Persoons, A. Dalton Trans. 2003, 2335.

(38) Laurent, F.; Plantalech, E.; Donnadieu, B.; Jiménez, A.; Hernández, F.; Martínez-Ripoll, M.; Biner, M.; Llobet, A. Polyhedron 1999, 18, 3321.

(39) Maurer, J.; Linseis, M.; Sarkar, B.; Schwederski, B.; Niemeyer, M.; Kaim, W.; Záliš, S.; Anson, C.; Zabel, M.; Winter, R. F. J. Am. Chem. Soc. 2008, 130, 259.

(40) Coe, B. J.; Harris, J. A.; Asselberghs, I.; Persoons, A.; Jeffery, J. C.; Rees, L. H.; Gelbrich T.; Hursthouse, M. B. J. Chem. Soc., Dalton Trans. 1999, 3617.

(41) (a) Oudar, J. L.; Chemla, D. S. J. Chem. Phys. 1977, 66, 2664. (b) Oudar, J. L. J. Chem. Phys. 1977, 67, 446.

(42) Coe, B. J.; Foxon, S. P.; Harper, E. C.; Harris, J. A.; Helliwell, M.; Raftery, J.; Asselberghs, I.; Clays, K.; Franz, E.; Brunschwig, B. S.; Fitch, A. G. Dyes Pigments 2009, 82, 171.

(43) Coe, B. J.; Harris, J. A.; Asselberghs, I.; Wostyn, K.; Clays, K.; Persoons, A.; Brunschwig, B. S.; Coles, S. J.; Gelbrich, T.; Light, M. E.; Hursthouse, M. B.; Nakatani, K. Adv. Funct. Mater. 2003, 13, 347.

(44) Coe, B. J.; Pilkington, R. A. J. Phys. Chem. submitted. 


\section{Table of Contents Graphic}

New $\mathrm{Ru}^{\mathrm{II}}$ complexes of the tris(1-pyrazolyl)methane ligand display intense, broad visible absorptions due to metal-to-ligand charge-transfer transitions. Hyper-Rayleigh scattering, Stark spectroscopy and density functional theory are used to probe and rationalize their optical and electronic properties. These chromophores show relatively large first hyperpolarizabilities $\beta$ with substantial two-dimensional character, and comparisons are made with related $c i s-\left\{\mathrm{Ru}^{\mathrm{II}}\left(\mathrm{NH}_{3}\right)_{4}\right\}^{2+}$ complexes.

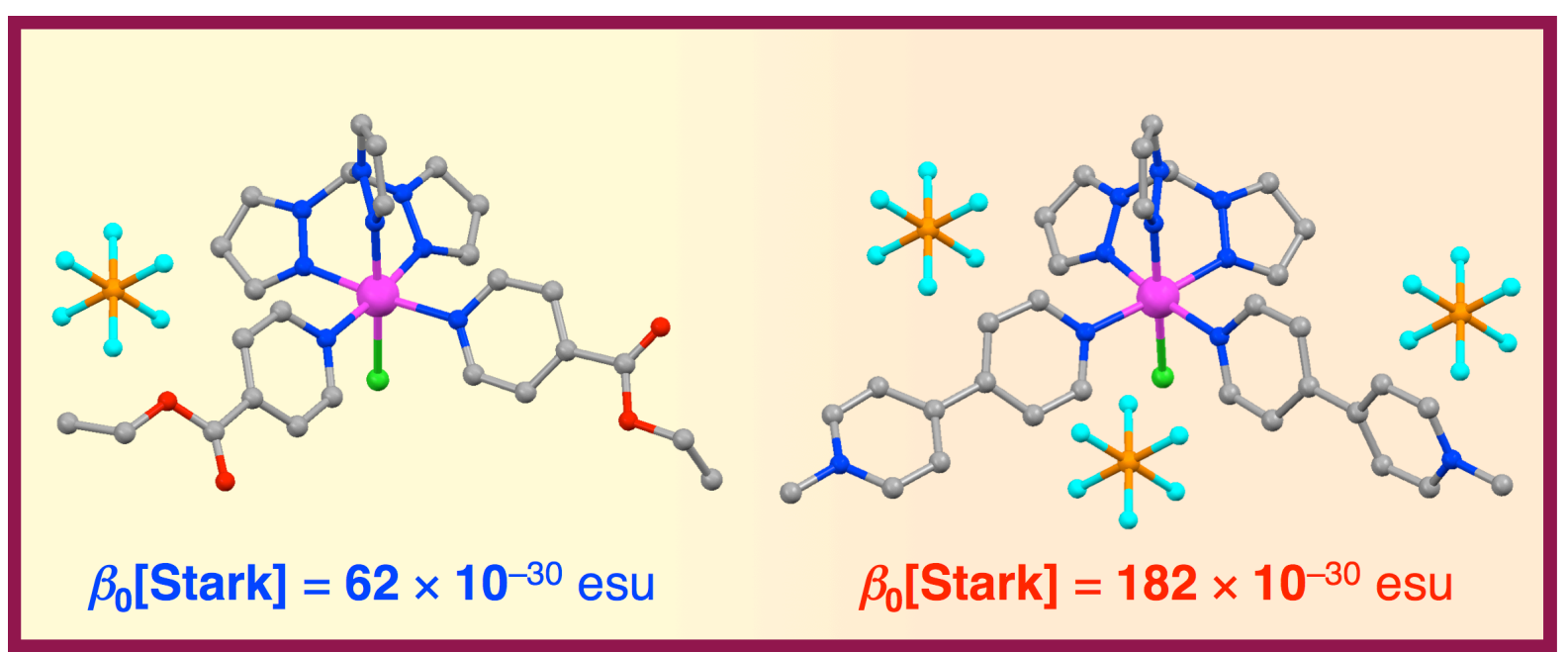

